AperTO - Archivio Istituzionale Open Access dell'Università di Torino

\title{
Exposure to follicular fluid during oocyte maturation and oviductal fluid during post-maturation does not improve in vitro embryo production in the horse
}

\section{This is a pre print version of the following article:}

Original Citation:

Availability:

This version is available http://hdl.handle.net/2318/1743319

since 2020-07-07T16:47:29Z

Published version:

DOI:10.1017/S096719941700048X

Terms of use:

Open Access

Anyone can freely access the full text of works made available as "Open Access". Works made available under a Creative Commons license can be used according to the terms and conditions of said license. Use of all other works requires consent of the right holder (author or publisher) if not exempted from copyright protection by the applicable law. 


\section{Zygote}

Date of delivery:

Journal and vol/article ref: ZYG 1700048

Number of pages (not including this page): 19

This proof is sent to you on behalf of Cambridge University Press.

Authors are strongly advised to read these proofs thoroughly because any errors missed may appear in the final published paper. This will be your ONLY chance to correct your proof. Once published, either online or in print, no further changes can be made.

\section{**THESE PROOFS SHOULD BE RETURNED WITHIN 2 WORKING DAYS**}

Please check the proofs carefully. Changes should be limited to the correction of editing and typographical errors and the answering of any author queries. Revision of the substance of the text is not permitted. Any corrections that contradict journal style will not be transferred.

Please return only ONE set of corrections.

HOW TO RETURN YOUR PROOFS

If you have no corrections to make, please email: nmarshall@cambridge.org with your approval of the proofs.

You can mark up proofs either on screen using the enabled electronic editing tools (our preferred method), or by hand on a hardcopy print-out which is then scanned and emailed.

Marking up electronically. All proofs are enabled to allow electronic annotation in the freely available Adobe Reader software. Using your cursor, select the text for correction and use the most appropriate single tool (i.e. 'Replace', 'Cross out', 'Insert' or 'Add note to text').

Please return the file as an attachment via email to:

Nicki Marshall

Email: nmarshall@cambridge.org

Marking up by hand. Alternatively, please print the PDF file, mark any amendments on the proofs and scan and email them to the address below:

Nicki Marshall

Email: nmarshall@cambridge.org

OR supply the corrections as a list, giving the line number of each correction, and email to Nicki Marshall at: nmarshall@ cambridge.org

\section{COPYRIGHT FORM:}

If you have not already done so, please download a copyright form from https://www.cambridge.org/core/iournals/zygote/information/transfer-copyright 


\section{Zygote}

the form. Failure to do so will delay publication of your article.

Thank you for publishing in Zygote. You will automatically receive a link to the PDF version of your article once it has been published online.

Please note:

- The proof is sent to you for correction of typographical errors only. Revision of the substance of the text is not permitted, unless discussed with the editor of the journal. Only one set of corrections are permitted.

- Please answer carefully any author queries.

- Corrections which do NOT follow journal style will not be accepted.

- A new copy of a figure must be provided if correction of anything other than a typographical error introduced by the typesetter is required.

- If you have problems with the file please contact nmarshall@cambridge.org

Please note that this pdf is for proof checking purposes only. It should not be distributed to third parties and may not represent the final published version.

Important: you must return any forms included with your proof.

\section{Please do not reply to this email}

\section{NOTE - for further information about Journals Production please consult our FAQs at} http://journals.cambridge.org/production_faqs 


\section{Author queries:}

Q1: The distinction between surnames can be ambiguous, therefore to ensure accurate tagging for indexing purposes online (eg for PubMed entries), please check that the highlighted surnames have been correctly identified, that all names are in the correct order and spelt correctly.

\section{Typesetter queries:}

\section{Non-printed material:}




\title{
Exposure to follicular fluid during oocyte maturation and oviductal fluid during post-maturation does not improve in vitro embryo production in the horse
}

\author{
Cécile Douet ${ }^{2}$, Olivia Parodi ${ }^{2}$, Nicola Antonio Martino ${ }^{3,4}$, Giovanni Michele Lacalandra ${ }^{5}$, \\ Michele Nicassio ${ }^{5}$, Fabrice Reigner ${ }^{6}$, Stefan Deleuze ${ }^{7}$, Maria Elena Dell'Aquila and Ghylène Goudet ${ }^{1}$ \\ PRC, INRA, CNRS, IFCE, Université de Tours, Nouzilly, France; Istituto Zooprofilattico Sperimentale per la Puglia e la \\ Basilicata, Foggia, Italy; Università degli Studi di Bari Aldo Moro, Dipartimento di Bioscienze, Biotecnologie e \\ Biofarmaceutica, Bari, Italy; Università degli Studi di Bari Aldo Moro, DETO, Bari Italy; PAO, INRA, Nouzilly, France; and \\ Faculté de Médecine vétérinaire, Département des Sciences Cliniques-Clinique Equine, Université de Liège, Liège, Belgium
}

Date submitted: 13.12.2016. Date revised/accepted: 25.07.2017

\section{Summary}

\begin{abstract}
Most wild equids and many domestic horse breeds are at risk of extinction, so there is an urgent need for genome resource banking. Embryos cryopreservation allows the preservation of genetics from male and female and is the fastest method to restore a breed. In the equine, embryo production in vitro would allow the production of several embryos per cycle. Intracytoplasmic sperm injection (ICSI) is used to generate horse embryos, but it requires expensive equipment and expertise in micromanipulation, and blastocyst development rates remain low. No conventional in vitro fertilization (IVF) technique for equine embryo production is available. The development of culture conditions able to mimic the maturation of the oocyte in preovulatory follicular fluid (pFF) and the post-maturation in oviductal fluid (OF) may improve embryo production in vitro. Our aim was to analyse the effect of in vitro maturation in $\mathrm{pFF}$ and incubation in $\mathrm{OF}$ on in vitro maturation of equine oocytes, fertilization using conventional IVF or ICSI, and embryo development after culture in synthetic oviductal fluid (SOF) or DMEM-F12. Oocytes collected from slaughtered mares or by ovum pick up were matured in vitro in pFF or semisynthetic maturation medium (MM). The in vitro maturation, fertilization and development rates were not statistically different between $\mathrm{pFF}$ and MM. After in vitro maturation, oocytes were incubated with or without OF. Post-maturation in OF did not significantly improve the fertilization and development rates. Thus, in our study, exposure to physiological fluids for oocyte maturation and post-maturation does not improve in vitro embryo production in the horse.
\end{abstract}

Keywords: Equine, IVM, IVF, Oocyte, Spermatozoa

\section{Introduction}

${ }^{1}$ All correspondence to: Ghylène Goudet, INRA, UMR 85, Physiologie de la Reproduction et des Comportements, F37380 Nouzilly, France. Tel:+33 2474279 41. Fax: +332 47 4277 43. E-mail: ghylene.goudet@inra.fr

${ }^{2}$ PRC, INRA, CNRS, IFCE, Université de Tours, 37380 Nouzilly, France.

${ }^{3}$ Istituto Zooprofilattico Sperimentale per la Puglia e la Basilicata, Foggia, Italy.

${ }^{4}$ Università degli Studi di Bari Aldo Moro, Dipartimento di Bioscienze, Biotecnologie e Biofarmaceutica, 70010, Polo di Valenzano, Bari, Italy.

${ }^{5}$ Università degli Studi di Bari Aldo Moro, Dipartimento dell'Emergenza e Trapianti d'Organo (DETO), 70010 Polo di Valenzano, Bari Italy.
Most wild equids are currently endangered or threatened in the wild, such as the Asiatic wild ass or Grevy's zebra, as mentioned in the IUCN Red List of endangered animal species of the International Union for the Conservation of Nature (Adams et al., 2009). Moreover, many domestic horse breeds are at risk of

\footnotetext{
${ }^{6} \mathrm{PAO}$, INRA, 37380, Nouzilly, France.

${ }^{7}$ Faculté de Médecine vétérinaire, Département des Sciences Cliniques-Clinique Equine, Université de Liège, B-4000 Liège, Belgium.
} 
extinction, with less than 300 active breeding mares, and several breeds that are nearly extinct with fewer than 100 active breeding mares, such as the Faer Island pony in Denmark, Estonian draught horse in Estonia, Landais pony and Grand Noir du Berry donkey in France (Smits et al., 2012b). The actions that are currently undertaken to preserve endangered horse breeds include the creation of a Genome Resource Bank.

Genome resource banking requires cryopreservation of semen, oocytes and/or embryos. Embryo cryopreservation allows the preservation of genetics from both male and female and is the fastest method to restore a breed. In equids, embryo production in vivo is limited, as experimental induction of multiple ovulations has a low efficiency (Meyers-Brown et al., 2011) and routine induction of multiple ovulations is still ineffective (Smits et al., 2012b). Embryo production in vitro allows the production of several embryos per cycle (Hinrichs, 2012). Intracytoplasmic sperm injection (ICSI) has been widely adopted to generate horse embryos in vitro, both for scientific purposes and in the horse breeding industry (Choi et al., 2011; Hinrichs, 2012). This method allows the investigation of specific aspects of fertilization in the horse, such as sperm chromatin-ooplasm interactions, overcoming limited efficiency of in vitro sperm penetration through oocyte barriers. However ICSI requires expensive equipment and expertise in micromanipulation, and very few laboratories worldwide routinely produce equine embryos following ICSI. Moreover, blastocyst development rates following ICSI do not exceed $40 \%$ per cleaved oocyte (Hinrichs, 2012). Over the last decades, several attempts to establish an efficient in vitro fertilization (IVF) technique in the equine were performed. Palmer and collaborators published the first paper on IVF of equine oocytes (Bézard et al., 1989) and obtained the first and only two IVF-produced foals (Palmer et al., 1991) using preovulatory oocytes and fresh sperm treated with calcium ionophore. However, this technique did not yield IVF rates higher than 36\% (Palmer et al., 1991; Alm et al., 2001) and, although low IVF rates have been reported sporadically (Hinrichs et al., 2002), this technique was not repeatable (Mugnier et al., 2009). Dell'Aquila and collaborators reported a $32 \%$ rate of equine IVF after incubation of in vitro matured oocytes subjected to partial cumulus removal, with frozen sperm treated with heparin (Dell'Aquila et al., 1996) but these results could not be replicated (Dell'Aquila et al., 1997a, b). Low rates of IVF (0-36\%) were obtained by Alm and collaborators (Alm et al., 2001) after exposure of spermatozoa to calcium ionophore or heparin. Since then, no reports showing the efficiency of one of these IVF techniques have been published. In 2009 , a $60 \%$ rate of fertilized oocytes was reported after treatment of fresh spermatozoa with procaine to induce hyperactivated motility (McPartlin et al., 2009). Using the same technique, we obtained $37 \%$ of fertilized oocytes (Ambruosi et al., 2013), but Leemans and collaborators showed that equine IVF embryos fail to develop beyond the 8-16-cell stage (Leemans et al., 2015). Thus, to date, no efficient conventional IVF technique for equine embryo production in vitro is available.

During its journey in the follicle and the oviduct, the oocyte acquires factors necessary for fertilization and early development. The somatic environment is of crucial importance for oocyte preparation for fertilization and development (Coy et al., 2012; Aviles et al., 2010). The development of in vitro culture conditions able to mimic the maturation of the oocyte in follicular fluid and the post-maturation of the ovulated oocyte in OF may help to improve embryo production in vitro. For example, addition of follicular fluid to maturation medium of equine oocytes increases fertilization and cleavage rate (Dell'Aquila et al., 1997b). Pre-incubation of equine oocytes with OF or oviductal cells increases fertilization rate (Mugnier et al., 2009) (Ambruosi et al., 2013). Moreover, several studies have shown the crucial role played by the oviduct in the preparation of equine gametes for fertilization (Goudet, 2011).

Several media have been used for in vitro culture of equine zygotes in different labs: Synthetic OF (SOF) medium (Tremoleda et al., 2003), DMEM-F12-51445C medium (in ME Dell'Aquila laboratory), DMEM-F12D8437 medium (in G Goudet lab), DMEM-F12-D8900 medium (Choi et al., 2011; Martino et al., 2016). However, these medium have never been used in the same laboratory and conditions.

Our aim was to analyse the effect of in vitro maturation in follicular fluid and pre-incubation in $\mathrm{OF}$ on in vitro maturation, fertilization using conventional IVF or ICSI, and development of equine oocytes. For this purpose: (1) we compared a semi-synthetic in vitro maturation medium with preovulatory follicular fluid, in which maturation naturally occurs; (2) we analysed the influence of pre-incubation of oocytes with OF before fertilization, which occurs in vivo after ovulation of the oocyte into the oviduct; (3) we tested four culture media for the in vitro development of fertilized oocytes using conventional IVF or ICSI.

\section{Materials and Methods}

All procedures on animals were conducted in accordance with the guidelines for the care and use of laboratory animals issued by the French Ministry of Agriculture and with the approval of the ethical review 
committee (Comité d'Ethique en Expérimentation Animale Val de Loire) under numbers 2011/6 and 02701.01. The study was conducted in France and in Italy $\left(48^{\circ}\right.$ and $41^{\circ}$ North parallel) during two subsequent breeding seasons.

All chemicals were purchased from Sigma-Aldrich (Milano, Italy and St Quentin Fallavier, France) unless otherwise indicated.

\section{Collection of equine immature oocytes}

Equine immature cumulus-oocyte complexes (COCs) were collected during the breeding season either from slaughtered mares in commercial abattoirs in France and Italy or by transvaginal ultrasound-guided aspiration on experimental mares in France.

For COCs collection from slaughtered mares, ovaries from females of unknown reproductive history were obtained at local commercial abattoirs immediately after females were slaughtered. They were transported to the laboratory within $2 \mathrm{~h}$ in $0.9 \%(\mathrm{w} / \mathrm{v}) \mathrm{NaCl}$ at $32-38^{\circ} \mathrm{C}$. In the French laboratory, COCs were collected using the aspiration procedure previously described by Goudet and collaborators (Goudet et al., 2000). Briefly, the tunica albuginea was removed and all follicles larger than $5 \mathrm{~mm}$ were aspirated with an 18-gauge needle at $100 \mathrm{mmHg}$ of vacuum pressure, the ovaries were cut into thick sections with a scalpel blade to find other follicles within the ovarian stroma. Follicular fluids were examined under a stereomicroscope for COCs recovery. In the Italian laboratory, COCs were collected using the scraping procedure as previously described (Dell'Aquila et al., 2001). All follicles from 5 to $25 \mathrm{~mm}$ in diameter were opened with a scalpel blade and the granulosa cells layer scraped with a curette, COCs were identified in the collected mural granulosa cells by using a dissection microscope. In both laboratories, oocytes denuded of cumulus and degenerated oocytes showing shrunken, dense or fragmented cytoplasm, were discarded.

For COCs collection by transvaginal ultrasoundguided aspiration (ovum pick up: OPU), adult cyclic pony mares from our experimental stud were used. Ovarian activity was assessed by routine rectal ultrasound scanning to choose mares with several follicles from 5 to $25 \mathrm{~mm}$. Follicles were punctured by transvaginal ultrasound-guided aspiration with a double-lumen needle (length $700 \mathrm{~mm}$, outer diameter $2.3 \mathrm{~mm}$, internal diameter $1.35 \mathrm{~mm}$, Casmed, Cheam, Surrey, England) and a sectorial probe (Aloka SSD900) as previously described (Goudet et al., 1997). After follicular fluid aspiration, the follicle was flushed with PBS (Phosphate Buffered Saline, Dulbecco A, Oxoid, Basingstoke, Hampshire, England) and heparin (Choay, Sanofi Aventis $5000 \mathrm{IU} / \mathrm{ml}$ ) at $38^{\circ} \mathrm{C}$. All as- pirated fluids were examined for oocyte recovery, and oocytes denuded of cumulus or degenerated oocytes showing shrunken, dense or fragmented cytoplasm were discarded. During the collection procedure, mares were injected with detomidine (Medesedan ${ }^{\circledR}$, $0.25 \mathrm{ml} /$ animal i.v., $10 \mathrm{mg} / \mathrm{ml}$ detomidine, Centravet, Plancoet, France) and butorphanol (Dolore ${ }^{\circledR}, 0.6$ $\mathrm{ml} /$ animal i.v., $10 \mathrm{mg} / \mathrm{ml}$ butorphanol tartrate and $0.1 \mathrm{mg} / \mathrm{ml}$ benzethonium chloride, Centravet) for sedation and analgesia, dipyrone and butylscopolamine (Estocelan ${ }^{\circledR}, 15 \mathrm{ml} /$ animal i.v., $4 \mathrm{mg} / \mathrm{ml}$ butylscopolamine and $500 \mathrm{mg}$ sodique metamizole, Centravet) for analgesia and antispasmodia. After puncture, the mares received a preventive antibiotic injection (Depocilline, $20 \mathrm{ml} /$ animal i.m., benzylpenicillin $170.41 \mathrm{mg} / \mathrm{ml}$ Intervet, Beaucouze, France).

\section{In vitro maturation (IVM) of equine immature oocytes}

Just after collection, COCs were washed in Medium 199 with Earle's salts, 25 mM HEPES and $\mathrm{NaHCO}_{3}$ supplemented with $20 \%(\mathrm{v} / \mathrm{v})$ fetal calf serum (FCS) and $25 \mu \mathrm{g} / \mathrm{ml}$ gentamycin. They were then cultured in group of 10 to 30 for $27 \mathrm{~h}$ in an atmosphere of $5 \% \mathrm{CO}_{2}$ in air at $38.5^{\circ} \mathrm{C}$ in $100 \%$ humidity in $500 \mu \mathrm{l}$ of maturation medium (MM) or $100 \%$ equine preovulatory follicular fluid (pFF). The maturation medium was Medium 199 with Earle's salts supplemented with $20 \%$ (v/v) FCS and $50 \mathrm{ng} / \mathrm{ml}$ epidermal growth factor (Goudet et al., 2000). The equine $\mathrm{pFF}$ was collected by transvaginal ultrasoundguided aspiration on three adult cyclic pony mares from our experimental stud. Ovarian activity was assessed by routine rectal ultrasound scanning. At the emergence of a follicle larger than $33 \mathrm{~mm}$ in diameter, the mare was injected with 1500 IU human chorionic gonadotropin (hCG, i.v., Chorulon, Intervet). The preovulatory follicle was punctured $35 \mathrm{~h}$ after hCG injection, just before ovulation, by transvaginal ultrasound-guided aspiration with a single-lumen needle (length $600 \mathrm{~mm}$, outer diameter $1.8 \mathrm{~mm}$, Thiebaud Freres, Jouvernex Margencel, France) and a sectorial probe as previously described. The presence of a metaphase II oocyte was ascertained using nuclear chromatin configuration analysis as described below. The $\mathrm{pFF}$ was centrifuged at $1500 \mathrm{~g}$ for $10 \mathrm{~min}$ at $4^{\circ} \mathrm{C}$. The supernatants were pooled and kept at $-20^{\circ} \mathrm{C}$.

\section{Post-maturation of equine oocytes in $\mathrm{OF}$}

After IVM, equine COCs were partially denuded and incubated in droplets of $30 \mu \mathrm{l}$ of porcine OF for $30 \mathrm{~min}$ in an atmosphere of $5 \% \mathrm{CO}_{2}$ in air at $38.5^{\circ} \mathrm{C}$ in $100 \%$ humidity. For porcine OF collection, genital tracts from gilts were obtained at a commercial abattoir and transported to the laboratory at room temperature. 
Genital tracts with both ovaries containing several follicles larger than $5 \mathrm{~mm}$ were used. The oviducts were dissected free from surrounding tissues. The oviductal content from the ampulla was expelled by gentle squeezing using a sterile microscope slide and collected by introducing the tip of a pipette into the ampulla and aspirating while making a manual ascendant pressure from the isthmus to the ampulla (Carrasco et al., 2008). After centrifugation at 10,000 $\mathrm{g}$ for $15 \mathrm{~min}$, the supernatant containing secreted and intracellular components was immediately stored at $-20^{\circ} \mathrm{C}$ until use as 'OF'.

\section{In vitro fertilization (IVF) procedure}

The IVF procedure was performed in France, using oocytes collected from slaughtered mares or by OPU.

\section{Preparation of equine sperm and IVF}

Fresh equine semen was collected with a closed artificial vagina from three adult Welsh pony stallions of proven fertility from our experimental stud. Semen was filtered through gauze, sperm motility was visually evaluated under light microscopy on a heated stage and sperm concentration was assessed using a spectrophotometer (Ciba-Geigy). Then, $1 \mathrm{ml}$ of semen was diluted in $2 \mathrm{ml}$ of pre-warmed modified Whitten's Medium (MW; $100 \mathrm{mM} \mathrm{NaCl}, 4.7 \mathrm{mM} \mathrm{KCl}, 1.2 \mathrm{mM}$ $\mathrm{MgCl}_{2}, 22 \mathrm{mM}$ HEPES, $4.8 \mathrm{mM}$ lactic acid hemicalcium salt, $1 \mathrm{mM}$ pyruvic acid) supplemented with $5.5 \mathrm{mM}$ glucose (anhydrous), pH 7.25 (McPartlin et al., 2009). Diluted sperm was transported to the laboratory within a few minutes at $37^{\circ} \mathrm{C}$ and centrifuged in $15 \mathrm{ml}$ conical tubes at $100 \mathrm{~g}$ for $1 \mathrm{~min}$ at $37^{\circ} \mathrm{C}$ to remove particulate matter and dead sperm. The supernatant was then transferred to a $14 \mathrm{ml}$ roundbottom tube and centrifuged at $600 \mathrm{~g}$ for $5 \mathrm{~min}$ at $37^{\circ} \mathrm{C}$. The pellet was re-suspended in $1.5 \mathrm{ml}$ of pre-warmed MW supplemented with glucose, and the concentration was determined by counting on a Thoma chamber under a microscope (Olympus, IMT2, Paris, France). Spermatozoa were then diluted at $10 \times 10^{6} / \mathrm{ml}$ in pre-warmed MW supplemented with $5.5 \mathrm{mM}$ glucose, $25 \mathrm{mM} \mathrm{NaHCO} 3$ and $7 \mathrm{mg} / \mathrm{ml}$ BSA, pH 7.25 (capacitating MW) (McPartlin et al., 2009). Spermatozoa were incubated in $500 \mu \mathrm{l}$ aliquots in polyvinyl alcohol-coated $5 \mathrm{ml}$ round-bottom tubes at $37^{\circ} \mathrm{C}$ in a humidified atmosphere during 6 $\mathrm{h}$. The motility was visually evaluated under a microscope (Olympus, IMT-2, Paris, France) at the beginning and at the end of the incubation period. Spermatozoa were then diluted at $1 \times 10^{6} / \mathrm{ml}$ in capacitating MW supplemented with $5 \mathrm{mM}$ procaine to induce hyperactivated motility. Droplets of $100 \mu \mathrm{l}$ of spermatozoa suspension were laid down onto culture dishes and covered with mineral oil.
Equine oocytes were washed in capacitating MW and groups of 10 were transferred to droplets of $100 \mu \mathrm{l}$ of spermatozoa suspension and co-incubated for $18 \mathrm{~h}$ in an atmosphere of $5 \% \mathrm{CO}_{2}$ in air at $38.5^{\circ} \mathrm{C}$ in $100 \%$ humidity.

\section{Control of parthenogenetic activation}

Equine oocytes were washed in capacitating MW and transferred to droplets of $100 \mu$ l of capacitating MW supplemented with $5 \mathrm{mM}$ procaine without spermatozoa and incubated for $18 \mathrm{~h}$ in an atmosphere of $5 \% \mathrm{CO}_{2}$ in air at $38.5^{\circ} \mathrm{C}$ in $100 \%$ humidity.

In vitro culture of equine zygotes

After $18 \mathrm{~h}$ co-incubation with spermatozoa, equine zygotes were washed in the culture medium and flushed to remove attached spermatozoa. Groups of 10 were transferred to droplets of $30 \mu \mathrm{l}$ of culture medium for $30 \mathrm{~h}$ or $54 \mathrm{~h}$ ( $48 \mathrm{~h}$ or $72 \mathrm{~h}$ post IVF) in an atmosphere of $5 \% \mathrm{CO}_{2}, 5 \% \mathrm{O}_{2}$ and $90 \% \mathrm{~N}_{2}$ at $38.5^{\circ} \mathrm{C}$ in $100 \%$ humidity.

Four culture media were tested. Synthetic OF (SOF) medium was SOF (Minitub) supplemented with $2 \%$ Basal Medium Eagle amino acids solution, $1 \%$ Minimum Essential Medium non-essential amino acids solution, $0.33 \mathrm{mg} / \mathrm{ml}$ sodium pyruvate, $6 \mathrm{mg} / \mathrm{ml}$ BSA fatty acid free, $5 \%$ FCS and $25 \mu \mathrm{g} / \mathrm{ml}$ gentamycin. DMEM-F12-51445C medium was Dulbecco's Modified Eagle's Medium Ham's Nutrient Mixture F12 with $3151 \mathrm{mg} / 1$ dextrose, $2.5 \mathrm{mM}$ L-glutamine, 15 $\mathrm{mM}$ HEPES, $55 \mathrm{mg} / 1$ sodium pyruvate (ref. $51445 \mathrm{C}$ ) supplemented with $10 \%$ FCS and $25 \mu \mathrm{g} / \mathrm{ml}$ gentamycin. DMEM-F12-D8437 medium was DMEM-F12 with $2.5 \mathrm{mM}$ L-glutamine, $15 \mathrm{mM}$ HEPES, $1.2 \mathrm{~g} / 1$ sodium bicarbonate (ref D8437) supplemented with $10 \%$ FCS and $25 \mu \mathrm{g} / \mathrm{ml}$ gentamycin. DMEM-F12-D8900 medium was DMEM-F12 with $2.5 \mathrm{mM}$ L-glutamine and $15 \mathrm{mM}$ HEPES (ref D8900) supplemented with $1.2 \mathrm{~g} / 1 \mathrm{NaHCO}_{3}, 10 \% \mathrm{FCS}$ and $25 \mu \mathrm{g} / \mathrm{ml}$ gentamycin. The three references of DMEM-F12 had identical composition but different forms (liquid or powder, sodium bicarbonate included or added subsequently).

\section{Assessment of nuclear status}

Nuclear status was assessed either after $27 \mathrm{~h}$ IVM, after $18 \mathrm{~h}$ IVF or after $30 \mathrm{~h}$ or $54 \mathrm{~h}$ in vitro development. Oocytes and zygotes were washed by aspiration in and out of a pipette in PBS, fixed in $4 \%$ paraformaldehyde in PBS for $20 \mathrm{~min}$ at room temperature, washed in PBS and processed for DNA and nuclear membrane staining. They were incubated for $30 \mathrm{~min}$ at room temperature in $0.2 \%$ Triton X-100 in PBS. Non-specific reactions were blocked by incubation for $1 \mathrm{~h}$ at room temperature in $10 \%$ goat serum in PBS. Oocytes and zygotes were incubated overnight at $4^{\circ} \mathrm{C}$ or $2 \mathrm{~h}$ at room temperature with an anti-lamin A/C antibody (ThermoScientific) diluted 1:100 in PBS containing 
$0.2 \%$ BSA and $0.1 \%$ Tween. After four washings for $5 \mathrm{~min}$ in PBS containing $0.2 \%$ BSA and $0.1 \%$ Tween, they were incubated for $1 \mathrm{~h}$ at room temperature with an AlexaFluor 594-conjugated-anti-mouse antibody (Life Technologies) diluted 1:400 in PBS. They were then washed five times for $5 \mathrm{~min}$ in PBS containing $0.1 \%$ Tween and two times for $5 \mathrm{~min}$ in PBS. They were incubated with $1 \mu \mathrm{g} / \mathrm{ml}$ bis-benzimide (Hoechst 33342) in PBS for $5 \mathrm{~min}$ and mounted on microscope slides in Mowiol V4-88 (133 mg/ml; Hoechst, Frankfurt, Germany) and $n$-propyl gallate $(5 \mathrm{mg} / \mathrm{ml})$. The slides were kept at $4^{\circ} \mathrm{C}$ in the dark until observation. Oocytes were observed under an epifluorescence microscope (Zeiss). Controls were performed using no primary antibodies to ascertain the absence of non-specific binding or no secondary antibodies to ascertain the absence of auto-fluorescence.

\section{Intracytoplasmic sperm injection (ICSI) procedure}

The ICSI procedure was performed in Italy, using oocytes collected from slaughtered mares and matured in vitro with the procedure described above.

\section{Preparation of equine sperm and ICSI procedure}

Fresh semen samples from three mature stallions with a reproductive history of normal fertility were used. The stallions were located in the reproductive centre Pegasus (Veterinary Clinics and Animal Productions Unit - DETO, Polo di Valenzano, University of Bari Aldo Moro, Valenzano, Bari, Italy) and were routinely used in artificial insemination programs. Semen was collected with a Missouri artificial vagina with an in-line gel filter, and was extended with INRA 96 (IMV Technologies, Piacenza, Italy) at a concentration of 20 to $25 \times 10^{6}$ sperm cells/ml and used immediately. Sperm cells for ICSI were prepared by the swim-up procedure in Earle's balanced salt solution supplemented with $0.4 \%$ BSA and $50 \mu \mathrm{g} / \mathrm{ml}$ gentamicin as previously described (Dell'Aquila et al., 2001, 2003; Ambruosi et al., 2009).

Intracytoplasmic sperm injection was carried out as previously reported (Ambruosi et al., 2009; Dell'Aquila et al., 2001, 2003). All procedures were performed at $38.5^{\circ} \mathrm{C}$ in Quinn's Advantage Fertilization HTF Universal medium (Cooper Surgical, Trumbull, CT, USA) supplemented with $5 \mathrm{mg} / \mathrm{ml}$ human serum albumin (HSA).

In vitro culture of embryos

In a first embryo culture experiment, aimed to test the influence of IVM medium (MM versus $p F F$ ) on fertilization and early embryonic development, injected oocytes were put immediately after ICSI in one of the two embryo culture medium (either DMEMF12-51445C or DMEM-F12-D8900 supplemented with $\left.1.2 \mathrm{~g} / 1 \mathrm{NaHCO}_{3}\right)$ plus 10\% FCS with $25 \mu \mathrm{g} / \mathrm{ml}$ gentamycin under mineral oil in droplets of $10 \mu \mathrm{l}$ and cultured individually for $72 \mathrm{~h}$ in a humidified atmosphere of $5 \% \mathrm{CO}_{2}, 5 \% \mathrm{O}_{2}$ and $90 \% \mathrm{~N}_{2}$ at $38.5^{\circ} \mathrm{C}$. At the end of the culture period, early embryos and uncleaved ova were removed from culture, fixed and evaluated using the procedures as described below. In a second embryo culture experiment, aimed to test the influence of pre-incubation with OF on embryo development, injected oocytes were cultured in DMEM-F12 D8900 for up to 10 days. At day 10 of culture, embryos (developed, delayed and degenerated embryos and uncleaved ova) were morphologically evaluated, fixed and stained for assessing nuclear chromatin, as described below.

Nuclear chromatin evaluation

Nuclear chromatin configuration of embryos and uncleaved ova was evaluated under an epifluorescence microscope (Nikon Eclipse 600 equipped with B-2 A, $346 \mathrm{~nm}$ excitation/460 $\mathrm{nm}$ emission filter) after staining with Hoechst 33258, as previously described (Dell'Aquila et al., 2001; Hinrichs et al., 2005; Lange Consiglio et al., 2009). Normally cleaved embryos were defined by the presence of nuclei of regular morphology within each blastomere. The number of morphologically normal nuclei was counted for each embryo. Embryos were classified as morulae when they had more than 32 nuclei. Embryos with more than 64 nuclei and having an outer layer of apparent differentiating trophoblast cells were considered to be blastocysts (Choi et al., 2006). In the group of uncleaved ova, normal fertilization was defined by the presence of two polar bodies with two pronuclei (PN). Oocytes showing one PN with intact sperm cell were classified as activated oocytes. Oocytes showing a metaphase plate and one polar body with an intact sperm cell were classified as unfertilized; oocytes having degenerated, irregularly clustered or faint chromatin were classified as degenerating.

\section{Statistical analysis}

The percentages of mature oocytes, fertilized oocytes, cleaved embryos, morulae and blastocysts were compared between groups using chi-square analysis. Differences were considered statistically significant at $P<0.05$.

\section{Results}

\section{Maturation rates after IVM}

After $27 \mathrm{~h}$ IVM in MM or pFF, nuclear status of the oocytes was assessed. Oocytes with metaphase II and one polar body were considered mature (Fig. 1a). 
Chromatin

a)

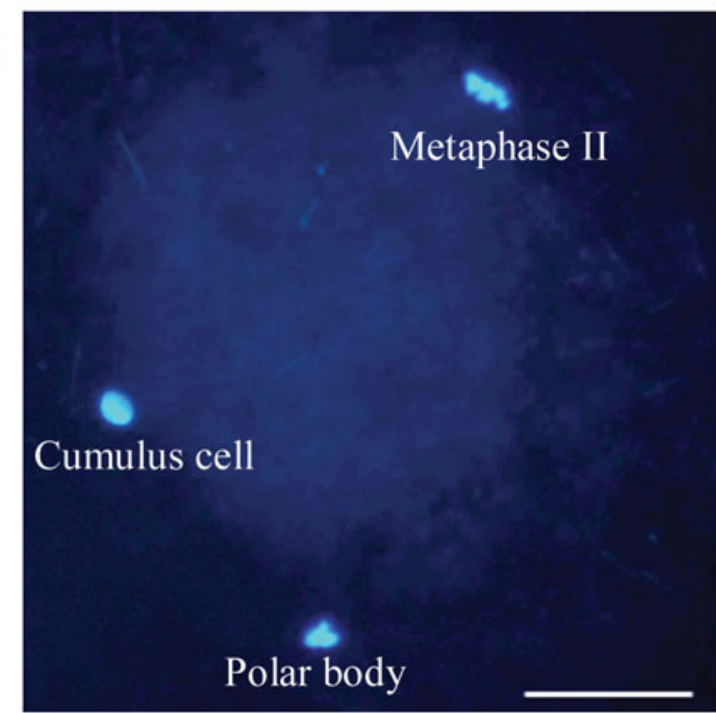

b)

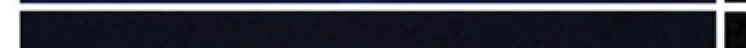

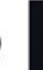

c)

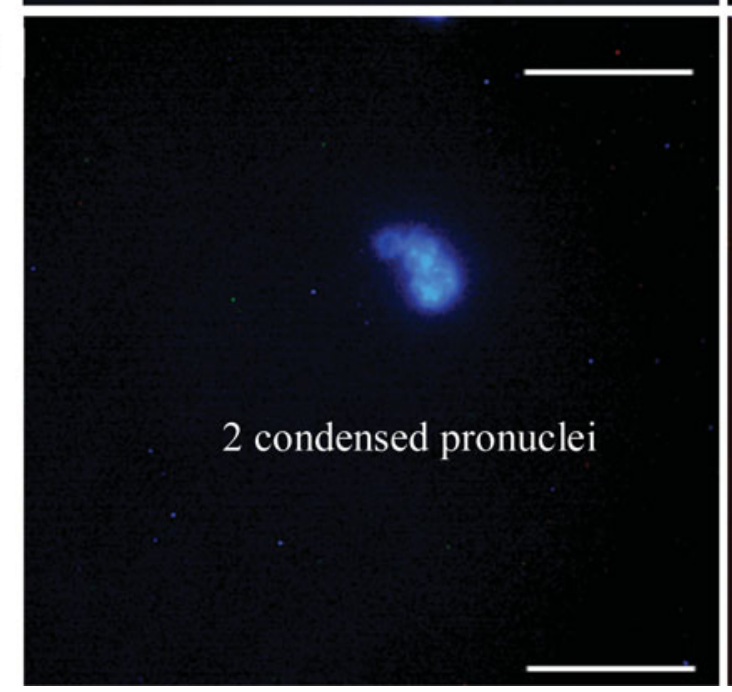

nuclear envelope
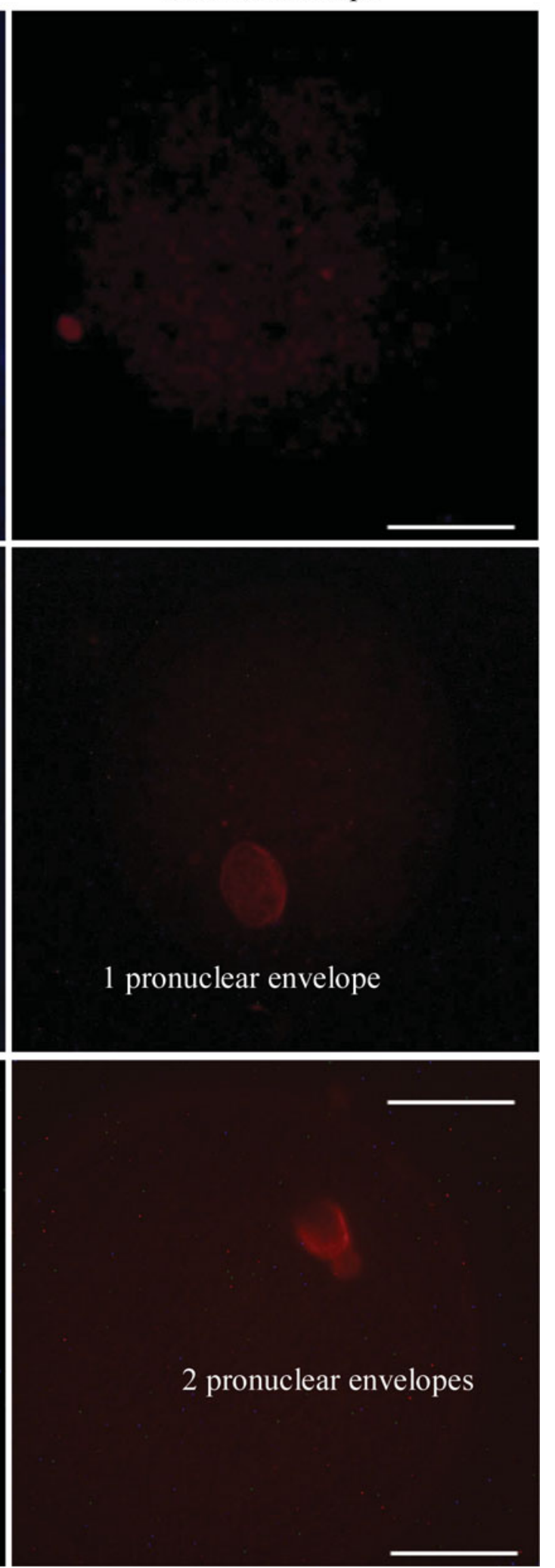

Figure 1 Nuclear status assessed by staining of chromatin with Hoechst stain and nuclear envelope by lamin A/C antibody. (a) Mature oocyte with metaphase II and one polar body with no detectable nuclear envelope. (b) Oocyte with one pronucleus showing chromatin and a nuclear envelope without sperm cell. (c) Oocyte with two condensed pronuclei with a compact mass of chromatin within the nuclear envelope. Scale bar represent $60 \mu \mathrm{m}$. 
For the oocytes collected in France, three repetitions were performed. After $27 \mathrm{~h}$ IVM in MM and pFF, 16 oocytes out of $21(76 \%)$ and 14 oocytes out of $21(67 \%)$ were mature. For the oocytes collected in Italy, seven repetitions were performed and in total, 219 oocytes were analysed after IVM. After $27 \mathrm{~h}$ IVM in MM and pFF, 57 oocytes out of 108 (53\%) and 60 oocytes out of $111(54 \%)$ were mature. In both experiments, the maturation rates in $\mathrm{MM}$ and $\mathrm{pFF}$ were not statistically different $(P>0.05)$.

\section{Fertilization and development rates after IVM, IVF and in vitro culture}

\section{Influence of IVM medium on fertilization rates after IVF} After oocytes collection from slaughterhouse or OPU, IVM in MM or pFF, post-maturation with OF and gametes co-incubation, nuclear status was assessed. We observed oocytes with metaphase II and one polar body with no detectable nuclear envelope (Fig. 1a), oocytes with one pronucleus (PN) showing DNA stained with Hoechst stain and a nuclear envelope stained positive with lamin A/C antibody without sperm cell (Fig. 1b) and oocytes with two PN in the cytoplasm, each PN showing the presence of DNA and a nuclear envelope (Fig. 1c). All the 2PN oocytes showed condensed PN with a compact mass of chromatin within the nuclear envelope and very few 2PN oocytes showed one or two polar bodies. Degenerated oocytes, having shrunken, dense or fragmented cytoplasm, were discarded.

For the oocytes collected in a slaughterhouse, three repetitions were performed (Fig. 2a). The percentage of oocytes containing $2 \mathrm{PN} 18 \mathrm{~h}$ post IVF was not statistically different between the two maturation conditions (IVM in MM: 22/33, 67\%; IVM in pFF: $24 / 42,57 \% ; P>0.05)$. For the oocytes collected by OPU, two repetitions were performed (Fig. $2 a$ ). The percentage of oocytes containing 2PN $18 \mathrm{~h}$ post IVF was not statistically different (IVM in MM: 4/10, $40 \%$; IVM in pFF: $4 / 9,44 \% ; P>0.05)$. When oocytes collected in a slaughterhouse and by OPU were pooled, the $2 \mathrm{PN}$ rates from $\mathrm{MM}(26 / 43,60 \%)$ and $\mathrm{pFF}$ $(28 / 51,55 \%)$ were not statistically different $(P>0.05)$.

\section{Influence of post-maturation with OF on fertilization rates after IVF}

After oocytes collection from slaughtered mares, IVM in $\mathrm{MM}$, pre-incubation or not with $\mathrm{OF}$ and gametes co-incubation, nuclear status was assessed. Two repetitions were performed (Fig. $2 b$ ). The percentage of oocytes containing $2 \mathrm{PN} 18 \mathrm{~h}$ post IVF was not statistically different between post-maturation with OF $(19 / 31,61 \%)$ and without OF $(17 / 34,50 \%)(P>$ $0.05)$.
Control of parthenogenetic activation

For the control groups for parthenogenetic activation, three repetitions were performed during the time of the experiments. Equine immature oocytes collected in France from slaughtered mares were in vitro matured in $\mathrm{MM}$ or $\mathrm{pFF}$, incubated with $\mathrm{OF}$ and coincubated with or without spermatozoa. Three oocytes containing 2 PN were observed in the control group incubated without spermatozoa $(3 / 26,11 \%$ and $0 / 7$ after IVM in MM and pFF respectively; Fig. $2 c$ ). In the other oocytes incubated without spermatozoa we observed either a metaphase II $(62 \%, 16 / 26$ and $57 \%$, $4 / 7)$ or $1 \mathrm{PN}(27 \%, 7 / 26$ and $43 \%, 3 / 7)$ after IVM in $\mathrm{MM}$ and pFF respectively. The percentage of $2 \mathrm{PN}$ oocytes was significantly different for incubation with vs without spermatozoa after IVM in MM and pFF ( $P$ $<0.05)$.

Development rates after IVM, IVF and in vitro culture After oocytes collection from slaughtered mares or by OPU, IVM in MM or pFF, post-maturation with OF, IVF and in vitro culture in one of the four tested media, nuclear status was assessed after $30 \mathrm{~h}$ in vitro culture, i.e. $48 \mathrm{~h}$ post IVF, or after $54 \mathrm{~h}$ in vitro culture, i.e. 72 $\mathrm{h}$ post IVF. For each medium, three repetitions were performed.

In total, 168 oocytes/embryos were analysed $48 \mathrm{~h}$ post IVF (39 from SOF, 45 from DMEM-F12-51445C, 42 from DMEM-F12-D8437 and 42 from DMEMF12-D8900). In 60 of them (36\%), we observed a metaphase II and a polar body or one pronucleus. In 89 of them (53\%), we observed two fully decondensed pronuclei: the chromatin was diffuse, some nucleoli were observed and the filamentous chromatin filled the whole nuclear envelope (Fig. 3a,c-e). Very few 2PN oocytes showed polar bodies. Moreover, pronuclear apposition was the dominant feature of these 89 oocytes (Fig. $3 a, c-e$ ). In 19 of the oocytes/embryos $(11 \%)$, we observed several nuclei (from three to 16 ) but the quality of these embryonic structures was poor as the cleavage was abnormal: the number of cells and nuclei were different and some cells had no or several nuclei (Fig. $3 b, f)$. The percentage of 2PN oocytes and abnormally cleaved embryos with respect to the number of non-degenerated oocytes for each culture medium is presented in Fig. 4.

After culture $48 \mathrm{~h}$ post IVF in SOF medium (Figs $3 a$ and $4 a$ ), the percentage of 2PN oocytes and abnormal embryos from slaughtered mares was not statistically different between the two maturation media $(73 \%$ for $\mathrm{MM}$ and $67 \%$ for $\mathrm{pFF} ; P>0.05$ ). One embryo (from $\mathrm{pFF}$ ) contained eight nuclei but no cleavage of the cytoplasm was observed. The percentage of 2PN oocytes and abnormal embryos from OPU was not statistically different between the two maturation 

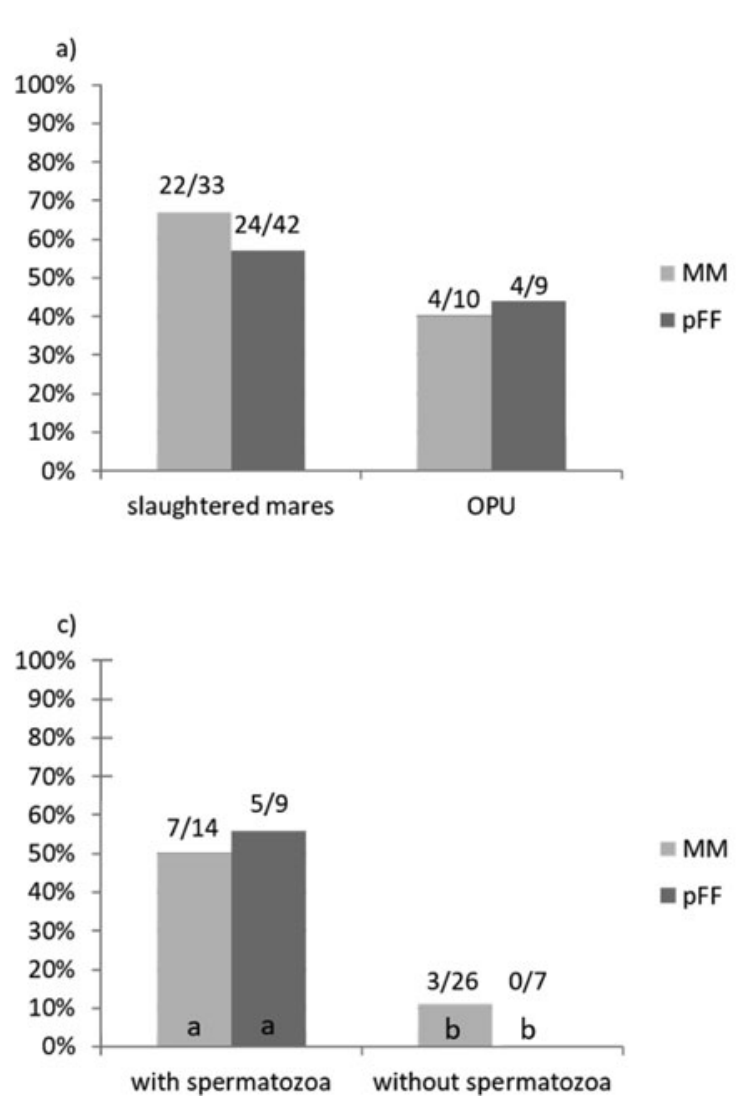

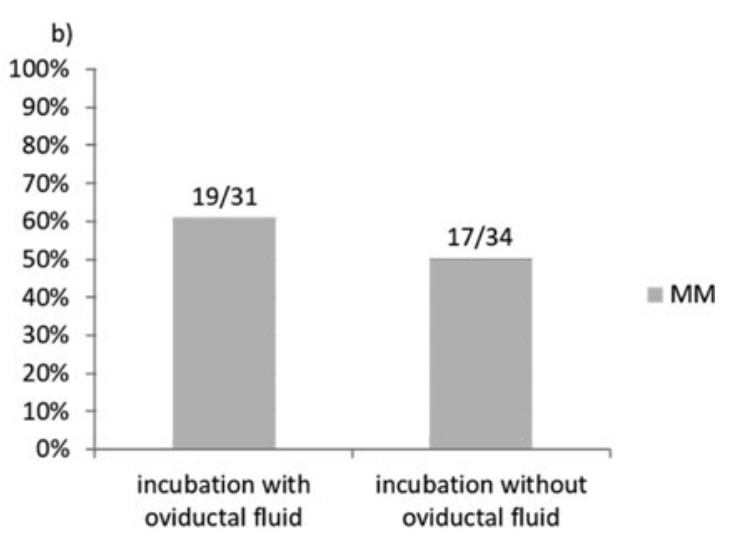

media $(60 \%$ for $\mathrm{MM}$ and $75 \%$ for $\mathrm{pFF}, P>0.05)$. Six embryos (three from MM and three from $\mathrm{pFF}$ ) contained from five to 16 nuclei, but the cleavage stopped at two to three cells (Fig. 3b). When oocytes collected in a slaughterhouse and by OPU were pooled, the percentages of $2 \mathrm{PN}$ oocytes and embryos from MM $(69 \%)$ and pFF $(70 \%)$ were not statistically different $(P>0.05)$.

After culture in DMEM-F12-51445C medium (Figs $3 c$ and $4 b$ ), the percentage of $2 \mathrm{PN}$ oocytes and abnormal embryos from slaughtered mares was not statistically different between the two maturation media (50\% for $\mathrm{MM}$ and $71 \%$ for $\mathrm{pFF}, P>0.05)$. Three embryos (one from MM and two from $\mathrm{pFF}$ ) contained from seven to 16 nuclei, however they did not cleave. The percentage of 2PN oocytes and abnormal embryos from OPU was not statistically different between the two maturation media $(50 \%$ for $\mathrm{MM}$ and $71 \%$ for $\mathrm{pFF}$, $P>0.05)$. No cleavage was observed. When oocytes from slaughterhouse and OPU were pooled, the percentages of 2PN oocytes and abnormal embryos from MM (50\%) and pFF (71\%) were not statistically different $(P>0.05)$.

After culture in DMEM-F12-D8437 medium (Figs 3d and $4 c$ ), the percentage of $2 \mathrm{PN}$ oocytes and abnormal embryos from slaughtered mares was not statistically different between the two maturation media $(75 \%$ for $\mathrm{MM}$ and $71 \%$ for $\mathrm{pFF}, P>0.05)$. One embryo (from MM) contained $12 \mathrm{PN}$, but no cleavage of the cytoplasm was observed. The percentage of $2 \mathrm{PN}$ oocytes and abnormal embryos from OPU was not statistically different between the two maturation media ( $80 \%$ for $\mathrm{MM}$ and $75 \%$ for $\mathrm{pFF}, P>0.05$, Fig. $4 \mathrm{c})$. No cleavage was observed. When oocytes collected in a slaughterhouse and by OPU were pooled, the percentages of 2PN oocytes and abnormal embryos from MM (76\%) and pFF (71\%) were not statistically different $(P>0.05)$. 


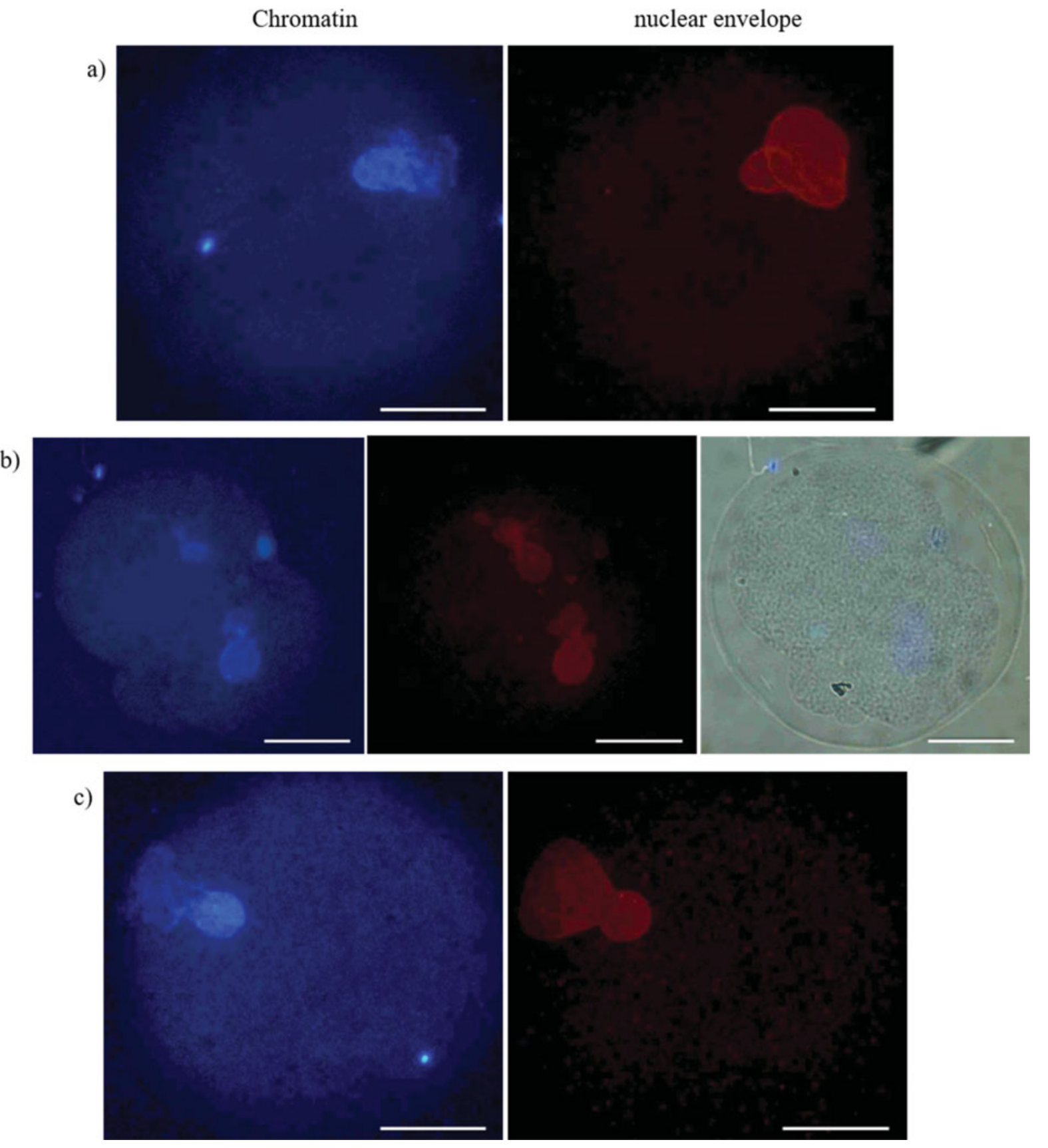

Figure 3 Nuclear status assessed by staining of chromatin with Hoechst and nuclear envelope by lamin A/C antibody. (a) An oocyte with two pronuclei fully decondensed after in vitro culture in SOF medium. (b) An abnormally cleaved embryo with two cells and four nuclei after in vitro culture in SOF medium. (c) An oocyte with two pronuclei fully decondensed after in vitro culture in DMEM-F12-51445C. (d) An oocyte with two pronuclei fully decondensed after in vitro culture in DMEM-F12-D8437. (e) An oocyte with two pronuclei fully decondensed after in vitro culture in DMEM-F12-D8900. ( $f$ ) An abnormally cleaved embryo with six cells and five nuclei after in vitro culture in DMEM-F12-D8900. Scale bar represent $60 \mu \mathrm{m}$.

After culture in DMEM-F12-D8900 medium (Figs $3 e$ and $4 d$ ), the percentage of 2PN oocytes and abnormal embryos from slaughtered mares was not statistically different between the two maturation media $(40 \%$ for $\mathrm{MM}$ and $57 \%$ for $\mathrm{pFF}, P>0.05$ ). Six embryos (two from $\mathrm{MM}$ and four from $\mathrm{pFF}$ ) contained from 3 to $10 \mathrm{PN}$ but the cleavage stopped at three to six cells (Fig. 3f).
The percentage of 2PN oocytes and abnormal embryos from OPU was not statistically different between the two maturation media ( $56 \%$ for MM and $67 \%$ for $\mathrm{pFF}$, $P>0.05$ ). Two embryos (from MM) contained three and nine nuclei, but the cleavage stopped at three to four cells with fragmentations. When oocytes from slaughterhouse and OPU were pooled, the percentages 


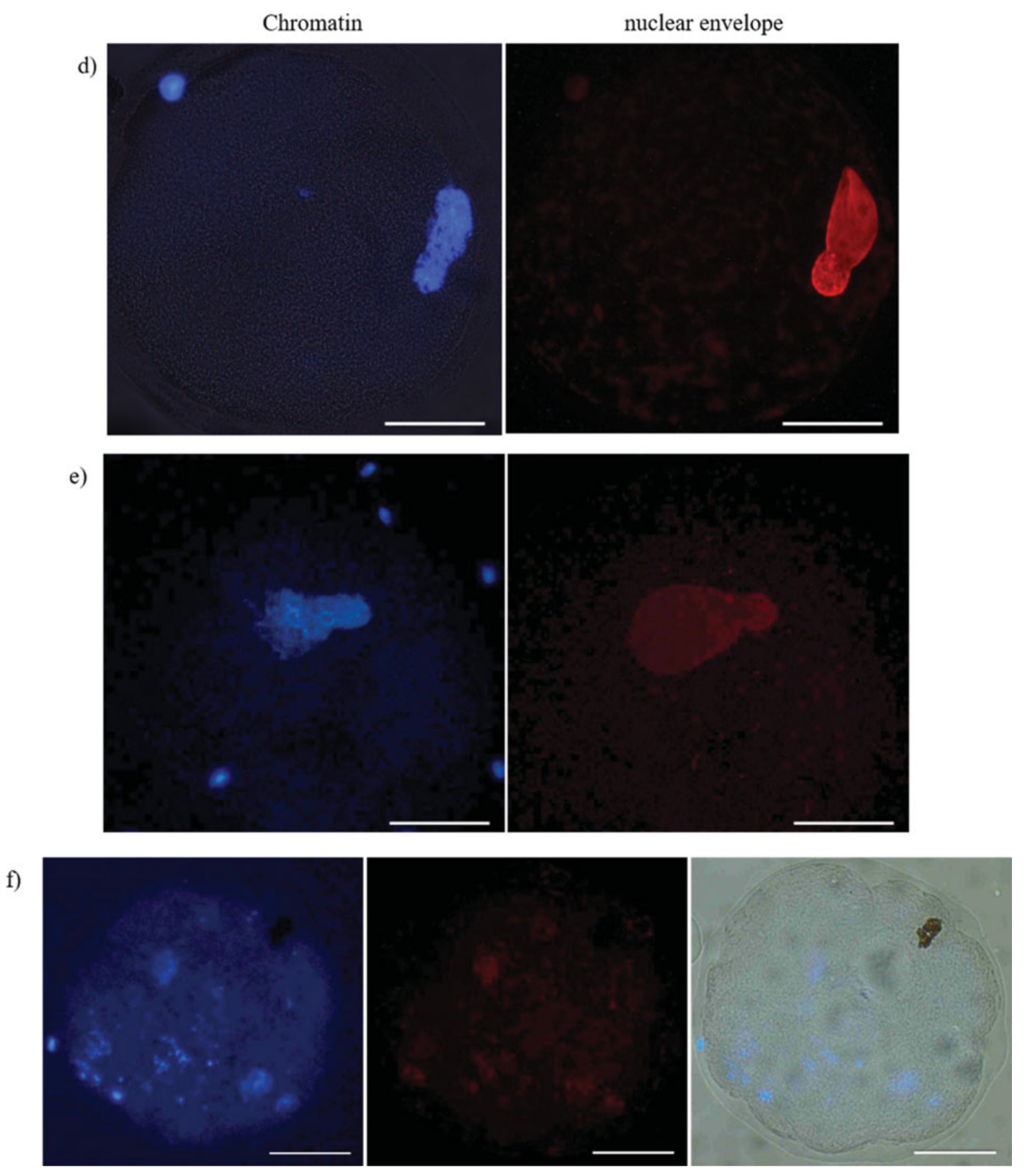

Figure 3 Continued.

of 2PN oocytes and abnormal embryos from MM (47\%) and pFF (61\%) were not statistically different $(P>$ 0.05).

Finally, when data from the four embryo culture media were pooled, the percentages of $2 \mathrm{PN}$ oocytes and abnormal embryos from MM (48/80, 60\%) and pFF $(60 / 88,68 \%)$ were not statistically different $(P>$ 0.05). Moreover, the percentages of abnormally cleaved embryos from MM (9/48, 19\%) and pFF (10/60, 17\%) were not statistically different $(P>0.05)$. As the four embryo culture media were not tested at the same time, no statistical comparison of these media was performed.

In total, 121 oocytes/embryos were analysed $72 \mathrm{~h}$ post IVF (40 from SOF, 26 from DMEM-F12-51445C, 37 from DMEM-F12-D8437 and 18 from DMEM-F12D8900). None of them went further in its development during these additional $24 \mathrm{~h}$ of culture, and most of 

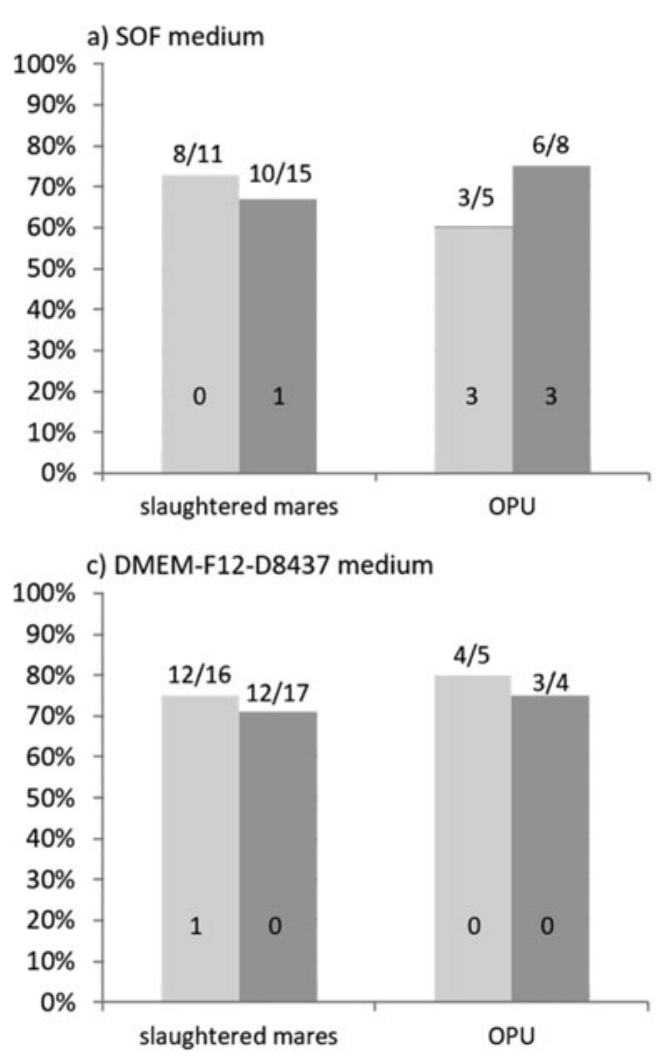
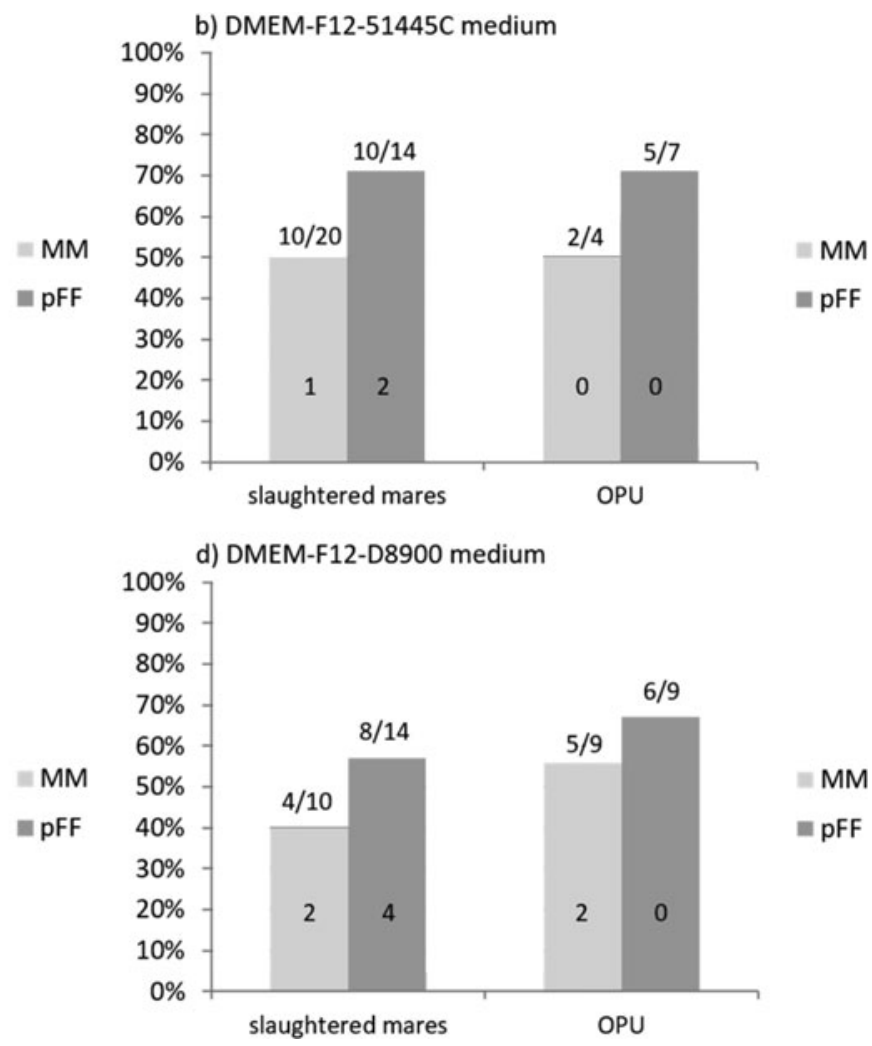

Figure 4 Percentage of 2PN oocytes and abnormally cleaved embryos after collection from slaughtered mares or by ovum pick up (OPU), in vitro maturation in maturation medium (MM) or preovulatory follicular fluid (pFF), incubation in oviductal fluid, in vitro fertilization and in vitro culture $48 \mathrm{~h}$ post IVF in (a) SOF medium; (b) DMEM-F12-51445C medium; (c) DMEMF12-D8437 medium; and (d) DMEM-F12-D8900 medium. The fractions at the top represent the number of 2PN oocytes and embryos out of the number of non-degenerated oocytes. The numbers at the bottom represent the number of abnormally cleaved embryos. The percentages were not statistically different between MM and $\mathrm{pFF}(P>0.05)$.

them degenerated (88\% from SOF, $88 \%$ from DMEMF12-51445C, 41\% from DMEM-F12-D8437 and 100\% from DMEM-F12-D8900).

\section{Fertilization and development rates after IVM, ICSI and in vitro culture}

Influence of IVM medium on fertilization and development rates $72 \mathrm{~h}$ after ICSI

After oocytes collection from slaughtered mares, IVM in MM or pFF, ICSI and in vitro culture for $72 \mathrm{~h}$, nuclear status was assessed. In total, 117 oocytes/embryos were analysed. Among these, 58 (50\%) were matured but not fertilized and 59 (50\%) were fertilized. Twentyfive $(21 \%)$ oocytes remained uncleaved after ICSI and $72 \mathrm{~h}$ in vitro culture. They showed two polar bodies (PB) and two pronuclei (PN) and were called zygotes.

In samples cultured in DMEM-F12-51445C, the total fertilization rate (including zygotes and cleaved embryos) did not differ significantly between the two IVM media $(18 / 36,50 \%$ versus $18 / 38,47 \%$, for $\mathrm{MM}$ and $\mathrm{pFF}$, respectively; $P>0.05$, Fig. $5 a$ ). In samples cultured in DMEM-F12-D8900, the total fertilization rate was higher in oocytes matured in pFF than in MM $(15 / 22,68 \%$ versus $8 / 21,38 \%$; $P<$ 0.05 , Fig. $5 b$ ). Independent of culture conditions, all zygotes either derived from in vitro culture in DMEMF12-51445C (Fig. 6a, b) or in DMEM-F12-D8900 (data not shown) showed decondensed pronuclei, their chromatin was diffuse, some nucleoli were observed and the filamentous chromatin filled the whole nuclear area. Pronuclear apposition was found in 37\% (7/19) of samples derived from in vitro culture in DMEM-F1251445C (2/9 after IVM in MM and 5/10 after IVM in $\mathrm{pFF}$ ) whereas it was never found in zygotes derived from in vitro culture in DMEM-F12-D8900.

The total cleavage rates with respect to the number of metaphase II (MII) injected oocytes for each IVM and culture medium are presented in Fig. 5. In both embryo culture media, the cleavage rates did not differ between maturation conditions: in DMEM-F12$51445 \mathrm{C}$, the total cleavage rates were $9 / 36(25 \%)$ versus $8 / 38(21 \%)$ for MM and pFF respectively $(P>0.05)$; in DMEM-F12-D8900, the total cleavage rates were $7 / 21$ $(33 \%)$ versus $10 / 22(45 \%)$ for MM and $\mathrm{pFF}$ respectively $(P>0.05)$. 


\section{a) DMEM-F12-51445C}

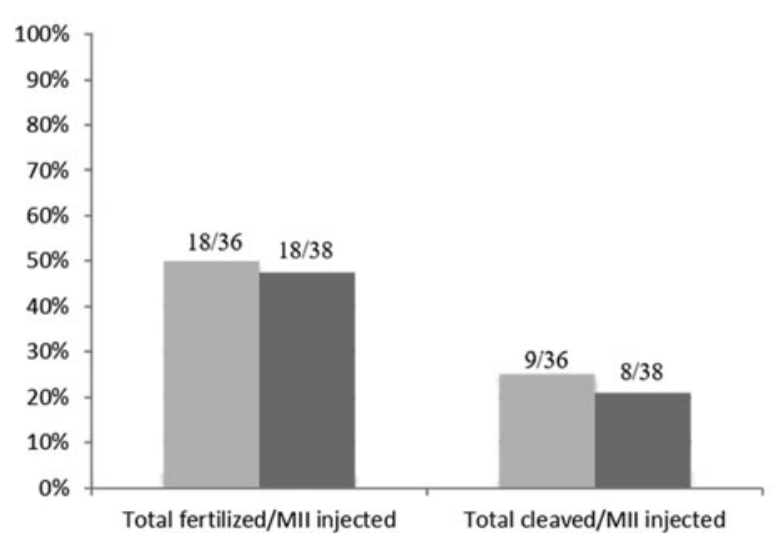

b) DMEM-F12-D8900

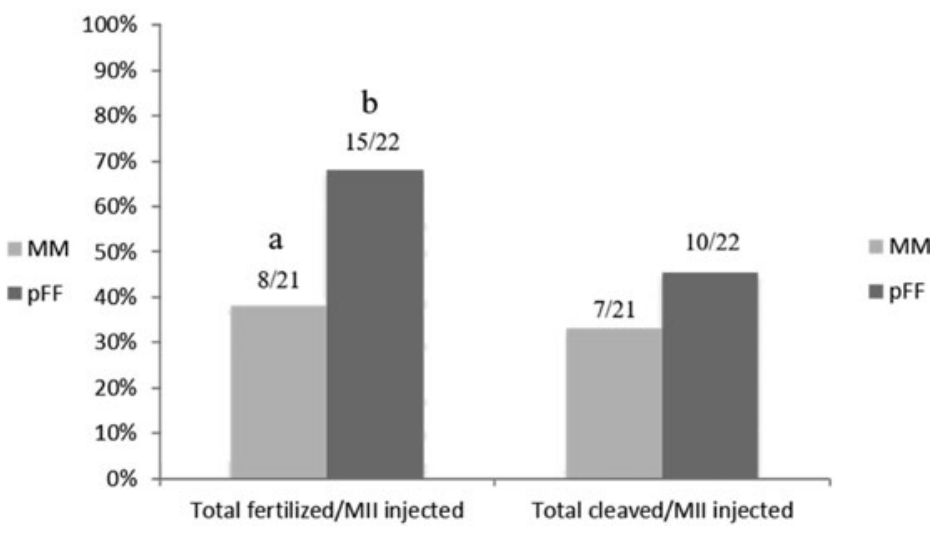

Figure 5 Percentage of fertilized oocytes (with respect to the number of mature oocytes) and cleaved embryos (with respect to the number of mature oocytes) after collection from slaughtered mares, in vitro maturation in maturation medium (MM) or preovulatory follicular fluid (pFF), in vitro fertilization by intracytoplasmic sperm injection (ICSI) and in vitro culture $72 \mathrm{~h}$ post-ICSI in (a) DMEM-F12-51445C medium; or (b) DMEM-F12-D8900 medium. The fractions at the top represent the number of fertilized oocytes out of the number of mature oocytes and the number of cleaved embryos out of the number of mature oocytes. Chi-squared test between maturation media: ${ }^{a, b} P<0.05$.

Representative micrographs of equine early embryos obtained after IVM in MM or in pFF, ICSI and $72 \mathrm{~h}$ in vitro embryo culture are presented in Fig. 6. Independent of culture conditions, most of the embryos, either derived from in vitro culture in DMEM-F12-51445C (Fig. 6e-h) or in DMEM-F12D8900, showed nuclei of regular morphology.

The percentages of zygotes and embryos at different developmental stages observed after IVM in MM or pFF, IVF by ICSI and in vitro culture in DMEMF12-51445C or in DMEM-F12-D8900 are reported in Table 1. Within each developmental stage (2PB2PN, 2-cell, 4-cell and 8/16-cell stage) no significant differences were found between the two IVM media. As the two embryo culture media were not tested at the same time, no statistical comparison of these two embryo culture media was performed.

By pooling data of embryo culture media (DMEM$\mathrm{F} 12-51445 \mathrm{C}+\mathrm{D} 8900$ in Table 1), no significant differences were found between oocytes matured in $\mathrm{MM}$ or $\mathrm{pFF}$.

\section{Influence of post-maturation with OF on fertilization and} development rates 10 days after ICSI

After oocytes collection from slaughtered mares, IVM in MM, post-maturation or not with OF, ICSI and in vitro culture, cleavage rates were assessed at day 3 and nuclear status was assessed at day 10 post-ICSI. Data are presented in Table 2 . The percentages of cleaved embryos at day 3 were not significantly different between oocytes incubated with OF $(62 \%, 29$ cleaved embryos/47 injected oocytes) or not $(65 \%, 28 / 43)$ $(P>0.05)$. The percentages of morula/MII injected oocytes at day 10 were not significantly different for oocytes incubated with OF $(4 \%, 2 / 47)$ compared with oocytes incubated without $(0 \%, 0 / 43)(P>0.05)$. The percentages of blastocyst/MII injected oocytes at day 10 were not significantly different between oocytes incubated with OF $(6 \%, 3 / 47)$ or without $(7 \%$, $3 / 43)(P>0.05)$. Representative micrographs of equine blastocysts obtained after IVM in MM, incubation or not in OF, ICSI and 10 days in vitro embryo culture in DMEM-F12-D8900 are presented in Fig. 7. They were observed either in culture (Fig. $7 a, b$ ) or after fixation and Hoechst staining (Fig. $7 c, d$ ). In this experiment, all blastocysts reached a good expansion level with a consistent number of nuclei of regular morphology.

\section{Discussion}

The aim of our work was to analyse the effect of IVM in follicular fluid and pre-incubation in OF on IVM, fertilization using conventional IVF or ICSI, and development of equine oocytes. We have been faced with the difficulty with equine oocyte collection. As the number of slaughtered mares is very low and the collection rate of equine oocytes is low compared with bovine oocytes for example (Hawley et al., 1995), the number of oocytes from slaughterhouses available for our experiments was low. Moreover, the collection of equine oocytes using OPU is expensive and timeconsuming, thus a maximum of 4 to $5 \mathrm{OPU}$ sessions per morning were performed, and the number of oocytes collected by OPU was low. The authors are aware of the small sample size in their experiments 


\section{MM}

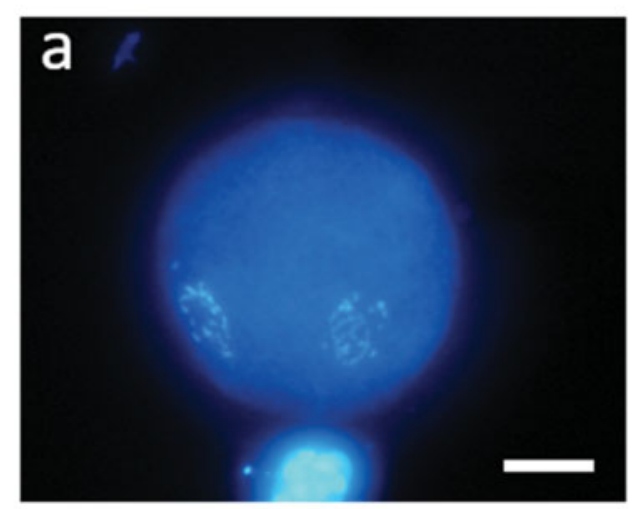

zygote
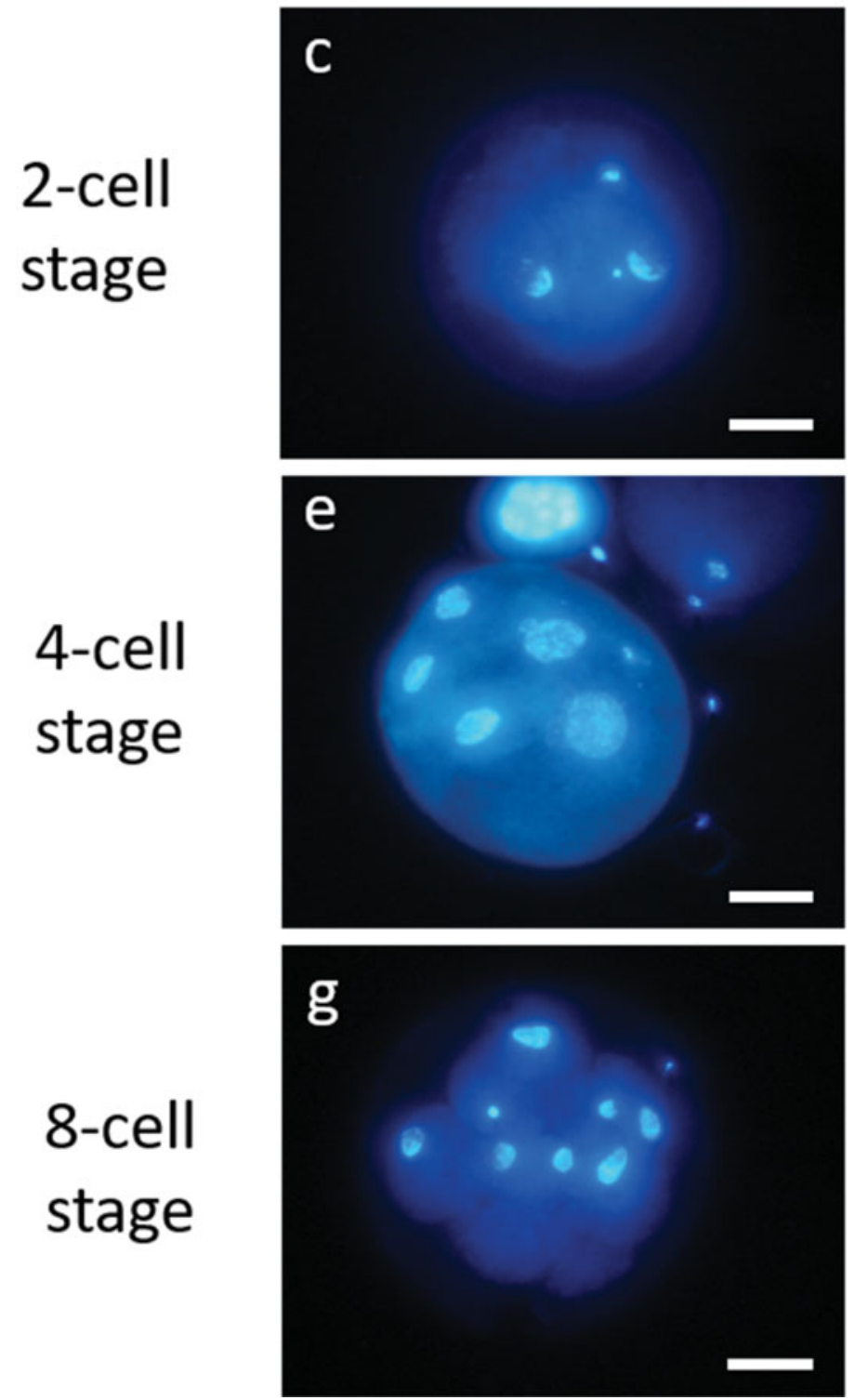

\section{$\mathrm{pFF}$}
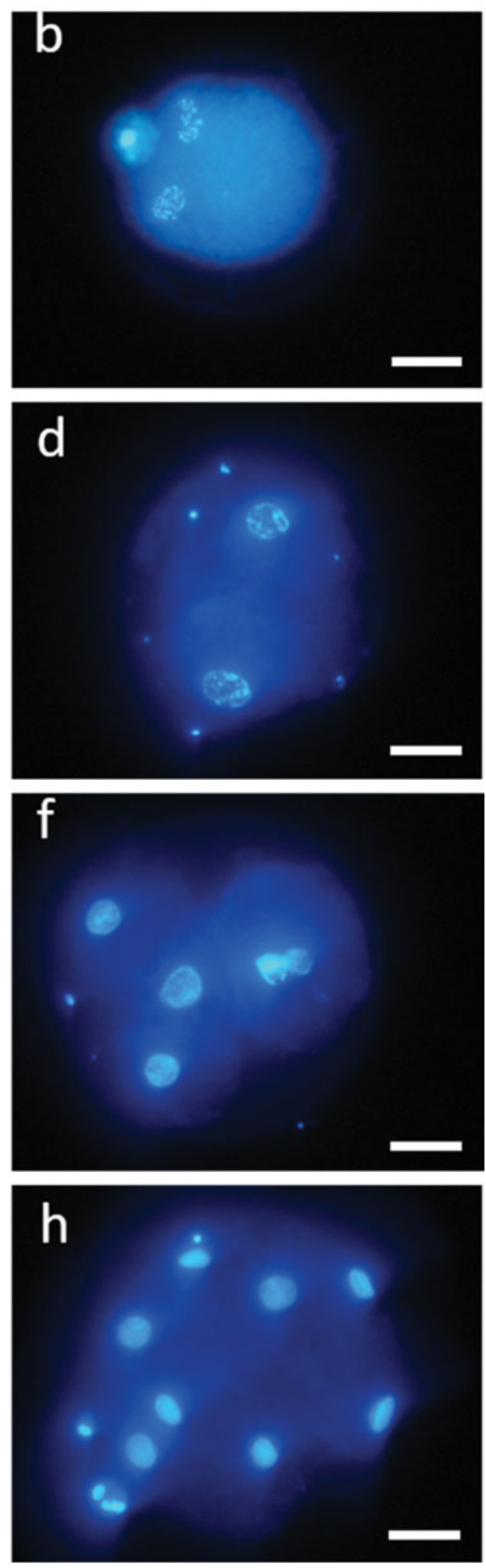

Figure 6 Representative photomicrographs of equine early embryos obtained after IVM in maturation medium (MM) or preovulatory follicular fluid $(\mathrm{pFF})$, fertilized by ICSI and in vitro cultured in DMEM-F12-51445C for $72 \mathrm{~h}$. Nuclear status assessed by chromatin staining with Hoechst and examined under ultraviolet (UV) light. $(a, b)$ Zygotes showing two decondensed pronuclei. $(c, d)$ Two-cell stage embryo. $(e, f)$ Four-cell stage embryo. $(g, h)$ Eight-cell stage embryo. Scale bar represent $60 \mu \mathrm{m}$. 


\section{With pre-incubation in oviductal fluid}
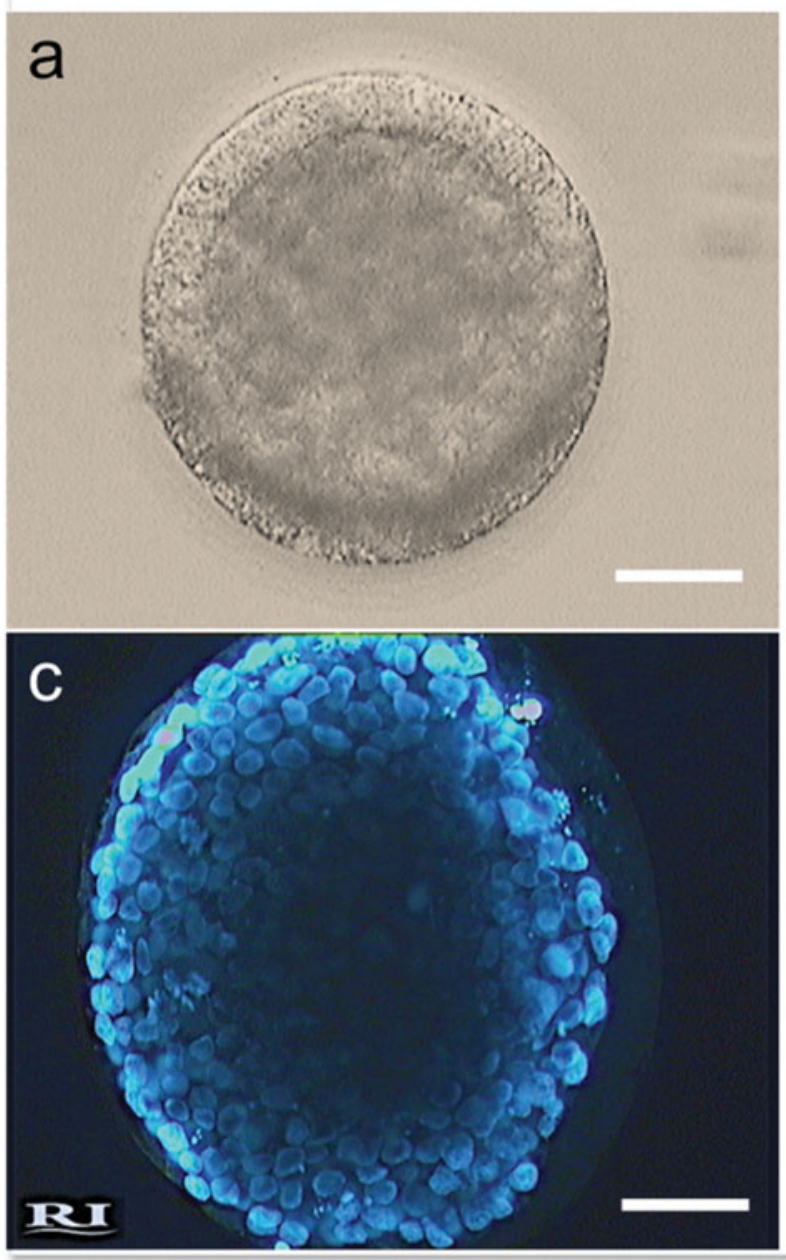

\section{Without pre-incubation in oviductal fluid}
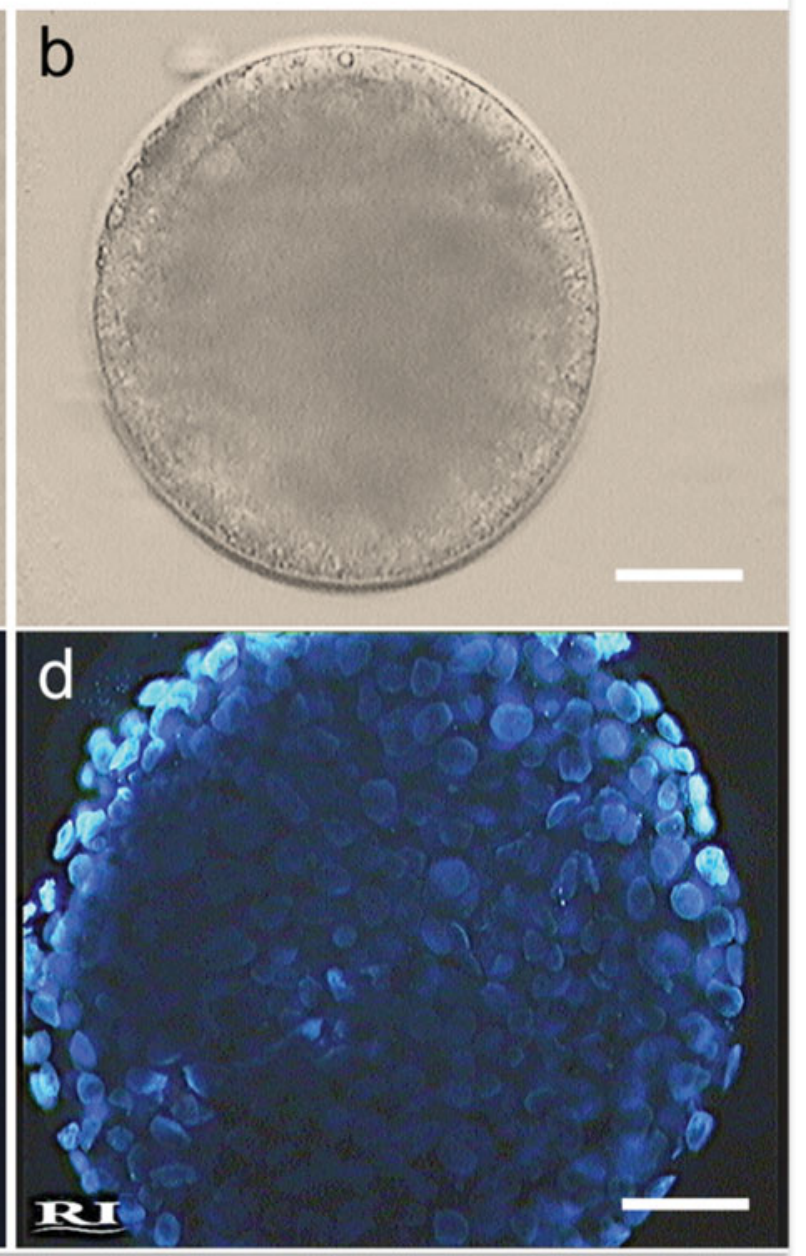

Figure 7 Representative photomicrographs of equine blastocysts obtained after IVM in maturation medium (MM), incubation or not in oviductal fluid and in vitro culture in DMEM-F12-D8900 for 10 days and observed under phase contrast $(a, b)$ or UV light $(c, d)$ after Hoechst staining. Two expanded blastocysts with the outer layer of trophoblastic cells and a high number of nuclei are shown. Scale bar represent $60 \mu \mathrm{m}$.

due to the difficulty in collecting equine oocytes, but the statistical tests have been adapted to small sample size and our conclusions are relevant.

Our first objective was to compare IVM in MM or preovulatory follicular fluid. Our hypothesis was that the low IVF and development rates observed in the equine may be due, at least partly, to a poor cytoplasmic maturation related to unsuited IVM conditions. Preovulatory follicular fluid, in which maturation naturally occurs, may sustain a better cytoplasmic maturation and thus a better competence for IVF and development. In our study, the nuclear maturation rates in $\mathrm{MM}$ and $\mathrm{pFF}$ were not statistically different, neither for the oocytes collected in France (76\% of the oocytes are in metaphase II in MM versus $67 \%$ in $\mathrm{pFF}$ ) nor for the oocytes collected in Italy ( $53 \%$ in $\mathrm{MM}$ versus $54 \%$ in $\mathrm{pFF}$ ). Thus, the semi-synthetic MM provides nuclear maturation rates similar to follicular fluid. In previous studies, the maturation rates of equine oocytes were similar: $68 \%$ in pFF (Caillaud et al., 2008), $54-58 \%$ in pFF (Conforti et al., 2005), 61\% in MM (Ambruosi et al., 2013), $71 \%$ in MM (Deleuze et al., 2009). In our study, the fertilization rates after ICSI were not different between maturation in MM (46\%) vs pFF (55\%). This result shows that the semi-synthetic MM supports cytoplasmic maturation to a similar extent to preovulatory follicular fluid. Moreover, the percentage of oocytes containing two pronuclei after IVF was not statistically different between maturation in $\mathrm{MM}$ 
Table 1 Percentage of equine zygotes (oocytes showing two polar bodies and two pronuclei, 2PB2PN) and embryos at different developmental stages after oocyte collection from slaughtered mares, IVM in maturation medium (MM) or preovulatory follicular fluid (pFF), intracytoplasmic sperm injection (ICSI) and in vitro culture in DMEM-F12-51445C medium or DMEM-F12-D8900 medium for $72 \mathrm{~h}$ post-ICSI

\begin{tabular}{|c|c|c|c|c|c|c|c|c|c|}
\hline \multirow{2}{*}{$\begin{array}{l}\text { IVM } \\
\text { medium }\end{array}$} & \multirow{2}{*}{$\begin{array}{l}\text { Embryo culture } \\
\text { medium }\end{array}$} & \multirow{2}{*}{$\begin{array}{c}\mathrm{N}^{\circ} \text { of cultured } \\
\text { oocytes }\end{array}$} & \multirow{2}{*}{$\begin{array}{l}\mathrm{N}^{\circ}(\%) \text { of MII and } \\
\text { injected oocytes }\end{array}$} & \multirow{2}{*}{$\begin{array}{l}\mathrm{N}^{\circ}(\%) \text { of total } \\
\text { fertilized oocytes }\end{array}$} & \multicolumn{5}{|c|}{$\mathrm{N}^{\circ}(\%)$ of zygotes and cleaved embryos found $72 \mathrm{~h}$ post-ICSI ${ }^{b}$} \\
\hline & & & & & $2 \mathrm{~PB} 2 \mathrm{PN}$ & 2-cell stage & 4-cell stage & 8/16-cell stage & Total cleaved \\
\hline MM & $\begin{array}{l}\text { DMEM-F12- } \\
\text { 51445C }\end{array}$ & 69 & $36(52)$ & $18(50)$ & $9(25)$ & $1(3)$ & $6(17)$ & $2(5)$ & $9(25)$ \\
\hline $\mathrm{pFF}$ & & 71 & $38(53)$ & $18(47)$ & $10(26)$ & $3(8)$ & $4(10)$ & $1(3)$ & $8(21)$ \\
\hline $\mathrm{MM}+\mathrm{pFF}$ & $\begin{array}{l}\text { DMEM-F12- } \\
51445 C\end{array}$ & 140 & $74(53)$ & $36(49)$ & $19(26)$ & $4(5)$ & $10(14)$ & $3(4)$ & $17(23)$ \\
\hline MM & DMEM-F12 D8900 & 39 & $21(54)$ & $8(38) *$ & $1(5)$ & $3(14)$ & $3(14)$ & $1(5)$ & $7(33)$ \\
\hline $\mathrm{pFF}$ & & 40 & $22(55)$ & $15(68) *$ & $5(23)$ & $5(23)$ & $2(9)$ & $3(14)$ & $10(46)$ \\
\hline $\mathrm{MM}+\mathrm{pFF}$ & DMEM-F12-D8900 & 79 & $43(54)$ & $23(53)$ & $6(14)$ & 8 (19) & $5(12)$ & $4(9)$ & $17(40)$ \\
\hline MM & $\begin{array}{l}\text { Total DMEM-F12- } \\
51445 \mathrm{C}+\mathrm{D} 8900\end{array}$ & 108 & $57(53)$ & $26(46)$ & $10(17)$ & $4(7)$ & $9(16)$ & $3(5)$ & $16(28)$ \\
\hline $\mathrm{pFF}$ & & 111 & $60(54)$ & $33(55)$ & $15(25)$ & $8(13)$ & $6(10)$ & $4(7)$ & $18(30)$ \\
\hline
\end{tabular}

${ }^{a}$ Numbers and percentages of fertilized oocytes out of the number of MII injected oocytes.

${ }^{b}$ Numbers and percentages of zygotes and cleaved embryos out of the number of MII injected oocytes.

Chi-squared test between media, for fertilization and cleavage rates: $* P<0.05$.

Table 2 Percentage of equine embryos at morula or blastocyst stages after oocyte collection from slaughtered mares, IVM in maturation medium (MM), incubation or not with OF, intracytoplasmic sperm injection (ICSI) and in vitro culture for 10 days post-ICSI in DMEM-F12-D8900

\begin{tabular}{|c|c|c|c|c|c|c|}
\hline $\begin{array}{l}\text { IVM } \\
\text { medium }\end{array}$ & $\begin{array}{l}\text { Pre-incubation with } \\
\text { oviductal fluid }\end{array}$ & $\begin{array}{l}\text { No. of cultured } \\
\text { oocytes }\end{array}$ & $\begin{array}{l}\text { No. (\%) of MII and } \\
\text { injected oocytes }\end{array}$ & $\begin{array}{l}\text { No. }(\%) \text { of morula } \\
\text { (day } 10)^{a}\end{array}$ & $\begin{array}{l}\text { No. }(\%) \text { of blastocyst } \\
\text { (day } 10)^{a}\end{array}$ & $\begin{array}{l}\text { No. }(\%) \text { of morula }+ \\
\text { blastocyst (day 10) }\end{array}$ \\
\hline MM & Pre-incubation & 103 & $47(46)$ & $2(4)$ & $3(6)$ & $5(11)$ \\
\hline MM & No pre-incubation & 109 & $43(39)$ & $0(0)$ & $3(7)$ & $3(7)$ \\
\hline Total & Total & 212 & $90(42)$ & $2(2)$ & $6(7)$ & $8(9)$ \\
\hline
\end{tabular}

${ }^{a}$ Numbers and percentages of embryos out of the number of MII injected oocytes. 
versus $\mathrm{pFF}$, neither for the oocytes collected in a slaughterhouse (67\% in $\mathrm{MM}$ versus $57 \%$ in $\mathrm{pFF}$ ) nor for the oocytes collected by OPU (40\% in MM versus $44 \%$ in $\mathrm{pFF}$ ). As very few oocytes containing two pronuclei extruded $\mathrm{PB}$, the significance of this nuclear stage may be questionable. One could hypothesize that either the PB were extruded and degenerated quickly or the expulsion of the PB did not occur as a consequence of an abnormal fertilization. On the one hand, using equine zygotes flushed from oviducts at different time intervals from ovulation and in vitro fertilized oocytes, Bézard and collaborators showed that PB degeneration and undetectability may occur quickly after fertilization both in vitro and in vivo (Bézard et al., 1989). On the other hand, Leemans and collaborators showed that the absence of the second polar body extrusion is due to oocyte cytokinesis induced by procaine instead of sperm penetration of equine oocytes (Leemans et al., 2015). In our study, the presence of some equine oocytes containing two pronuclei in the parthenogenetic control group incubated without spermatozoa supports this second hypothesis. Previous studies have shown that spontaneous parthenogenetic division of unfertilized equine oocytes is rare either in vitro or in vivo (Zhang et al., 1989; Zhang et al., 1990). Finally, after culture in embryo culture media, we observed no difference between maturation in MM vs pFF for the percentage of zygotes after ICSI (17\% vs. $25 \%$ respectively) and the percentage of cleaved embryos after ICSI $(28 \%$ versus 30\%). Thus, our MM and the preovulatory follicular fluid support the acquisition of competence for maturation, fertilization and development to a similar extent. However, in our conditions, IVM occurs in a static medium, whereas in vivo maturation naturally takes place in a dynamic medium in which subtle changes occur during final maturation of the preovulatory follicle. IVM in a culture system in which hormones would be added sequentially to mimic changes observed in vivo might provide better conditions for equine oocyte maturation. For example, porcine oocytes matured in a medium in which hormones were added sequentially exhibited greater developmental competence to blastocyst stage (Kawashima et al., 2008).

The influence of oviductal secretions on oocytes has been widely studied in mammals (Aviles et al., 2010; Coy et al., 2012; Lopera-Vasquez et al., 2015). A beneficial effect on equine oocytes has been observed with incubation of equine oocytes with OF collected 6 $\mathrm{h}$ after ovulation (Ambruosi et al., 2013) or co-culture of equine oocytes with equine or porcine oviduct epithelial cells (Mugnier et al., 2009). In our study, incubation of equine oocytes with OF collected before ovulation, at the end of follicular growth, did not influence fertilization or development rates. This result suggests that oviductal factors with a beneficial effect on oocyte may be present in the oviduct during a specific time interval after ovulation. Several oviductal factors, which influence fertilization rates, have been studied in the equine oviduct: Deleted in malignant brain tumour one is secreted in the oviduct from early follicular phase to post-ovulatory stage (Ambruosi et al., 2013) and osteopontin and atrial natriuretic peptide $A$ are present in the equine oviduct from emergence of the dominant follicle to preovulatory stage (Mugnier et al., 2009). Further studies are in progress to clarify the role and secretion pattern of oviductal factors with a beneficial effect on equine oocytes.

Several culture media have been used for in vitro development of equine fertilized oocytes. SOF medium has been used previously for in vitro culture of equine zygotes after ICSI with a cleavage rate of $61 \%$ (Tremoleda et al., 2003), 69\% (Galli et al., 2002) and 64\% (Lazzari et al., 2002) 48 h postICSI. In our conditions, $26 \%$ of the oocytes after IVF were abnormally cleaved and $74 \%$ contained two fully decondensed and apposed pronuclei. The pronuclei decondensation and apposition evidence the first step of embryo development. However, the lack of normal embryo cleavage throws doubt on the fertilization technique. The use of procaine during the IVF procedure in order to induce sperm hyperactivation may have a detrimental effect on oocytes and zygotes. Leemans and collaborators have shown that procaine induces oocyte cytokinesis and that cleaved oocytes did not develop beyond 8-16 cells with daughter cells containing aberrant DNA fragments (Leemans et al., 2015). DMEM-F12 medium has been used previously for in vitro culture of equine zygotes after ICSI with a cleavage rate of $68 \%$ (Smits et al., 2012a), 69\% (Choi et al., 2011) and 75\% (Choi et al., 2006) 3 days post-ICSI. Moreover, DMEM-F12 medium has been used previously for in vitro culture of equine zygotes after IVF with a cleavage rate of $66 \%$ (McPartlin et al., 2009). In our conditions, three references of DMEM-F12 were tested, with identical composition but different forms (liquid or powder, sodium bicarbonate included or added subsequently). Following ICSI and $72 \mathrm{~h}$ culture in DMEM-F12, the percentages of zygotes (26\% in DMEM-F12-51445C and $14 \%$ in DMEM-F12-D8900) and the percentages of cleaved embryos (23\% in DMEM-F12-51445C and $40 \%$ in DMEM-F12-D8900) were consistent, and the morphology of the ICSI embryos was normal. Following ICSI and 10 days culture in DMEM-F12D8900, the blastocysts formation rate was correct and repeatable and blastocysts quality was good, as blastocyst expansion and hatching throughout the zona pellucida were observed. Following IVF and culture in DMEM-F12, no normal embryo cleavage and 
development were observed. As the IVM and embryo culture media were the same in the IVF and ICSI experiments, it can be speculated that the IVM and embryo culture conditions are appropriate and that the IVF conditions have to be improved to increase the quality of the embryos and their developmental competence.

Thus, in our study, exposure to physiological fluids for oocyte maturation and post-maturation does not improve in vitro embryo production in the horse. In vitro culture of ICSI fertilized oocytes provides morphologically normal embryos. However, when procaine is used during IVF, no embryo able to develop properly is observed. Improving the IVF technique will improve the developmental competence of IVF embryos and bring them to a state in which they will be transferred into surrogate mares.

\section{Author's contributions}

MED and GG conceived of the study and participated in its design. CD, OP, FR, SD and GG performed the experiments and analysis in France, NAM, MN, GML and MED performed the experiments and analysis in Italy. MED and GG wrote the manuscript and all authors read and approved the final manuscript.

\section{Acknowledgements}

We would like to thank the staff of the experimental stud at the 'Unité Expérimentale de Physiologie Animale de l'Orfrasière (UEPAO)' for providing equine oocytes and sperm. We also thank Albert Arnould, Jean-Noël Couet, Thierry Delpuech, Pascal Papillier and Gaël Ramé at the 'Unité Mixte de Recherche de Physiologie de la Reproduction et des Comportements (UMR PRC)' and the staff of the slaughterhouses for technical help. This work has benefited from the facilities and expertise of the 'Plateforme d'Imagerie Cellulaire' (PIC) of the UMR 85 'Physiologie de la Reproduction et des Comportements'.

\section{Financial support}

This work was supported by the 'Institut Français du Cheval et de l'Equitation' (IFCE). NAM was supported by the Italian Ministry of Health, Project GR-201102351396.

\section{Conflict of interest}

The authors declare no conflict of interest.

\section{References}

Adams, G. P., Ratto, M. H., Collins, C. W. \& Bergfelt, D.R. (2009). Artificial insemination in South American camelids and wild equids. Theriogenology 71, 166-75.

Alm, H., Torner, H., Blottner, S., Nurnberg, G. \& Kanitz, W. (2001). Effect of sperm cryopreservation and treatment with calcium ionophore or heparin on in vitro fertilization of horse oocytes. Theriogenology 56, 817-29.

Ambruosi, B., Accogli, G., Douet, C., Canepa, S., Pascal, G., Monget, P., Moros, C., Holmskov, U., Mollenhauer, J., Robbe-Masselot, C., Vidal, O., Desantis, S. \& Goudet, G. (2013). Deleted in malignant brain tumor 1 is secreted in the oviduct and involved in the mechanism of fertilization in equine and porcine species. Reproduction 146, 119-33.

Ambruosi, B., Lacalandra, G. M., Iorga, A. I., De Santis, T., Mugnier, S., Matarrese, R., Goudet, G. \& Dell'aquila, M.E. (2009). Cytoplasmic lipid droplets and mitochondrial distribution in equine oocytes: Implications on oocyte maturation, fertilization and developmental competence after ICSI. Theriogenology 71, 1093-104.

Aviles, M., Gutierrez-Adan, A. \& Coy, P. (2010). Oviductal secretions: will they be key factors for the future ARTs? Mol. Hum. Reprod. 16, 896-906.

Bézard, J., Magistrini, M., Duchamp, G. \& Palmer, E. (1989). Chronology of equine fertilisation and embryonic development in vivo and in vitro. Equine Vet. J. Suppl. 8, 105-10.

Caillaud, M., Dell'aquila, M. E., De Santis, T., Nicassio, M., Lacalandra, G. M., Goudet, G. \& Gerard, N. (2008). In vitro equine oocyte maturation in pure follicular fluid plus interleukin-1 and fertilization following ICSI. Anim. Reprod. Sci. 106, 431-9.

Carrasco, L. C., Romar, R., Aviles, M., Gadea, J. \& Coy, P. (2008). Determination of glycosidase activity in porcine oviductal fluid at the different phases of the estrous cycle. Reproduction 136, 833-42.

Choi, Y. H., Love, C. C., Varner, D. D. \& Hinrichs, K. (2006). Equine blastocyst development after intracytoplasmic injection of sperm subjected to two freeze-thaw cycles. Theriogenology 65, 808-19.

Choi, Y. H., Varner, D. D., Love, C. C., Hartman, D. L. \& Hinrichs, K. (2011). Production of live foals via intracytoplasmic injection of lyophilized sperm and sperm extract in the horse. Reproduction 142, 529-38.

Conforti, V. A., Vanderwall, D. K. \& Woods, G.L. (2005). Effect of homologous follicular fluid from medium-sized and large follicles on in vitro maturation of equine cumulus-oocyte complexes. Reprod. Fertil. Dev. 17, 651-8.

Coy, P., Garcia-Vazquez, F. A., Visconti, P. E. \& Aviles, M. (2012). Roles of the oviduct in mammalian fertilization. Reproduction 144, 649-60.

Deleuze, S., Goudet, G., Caillaud, M., Lahuec, C. \& Duchamp, G. (2009). Efficiency of embryonic development after intrafollicular and intraoviductal transfer of in vitro and in vivo matured horse oocytes. Theriogenology 72, 2039.

Dell'Aquila, M. E., Albrizio, M., Maritato, F., Minoia, P. \& Hinrichs, K. (2003). Meiotic competence of equine oocytes and pronucleus formation after intracytoplasmic sperm 
injection (ICSI) as related to granulosa cell apoptosis. Biol. Reprod. 68, 2065-72.

Dell'Aquila, M. E., Cho, Y. S., Minoia, P., Traina, V., Fusco, S., Lacalandra, G. M. \& Maritato, F. (1997a). Intracytoplasmic sperm injection (ICSI) versus conventional IVF on abattoir-derived and in vitro-matured equine oocytes. Theriogenology 47, 1139-56.

Dell'Aquila, M. E., Cho, Y.S., Minoia, P., Traina, V., Lacalandra, G. M. \& Maritato, F. (1997b). Effects of follicular fluid supplementation of in-vitro maturation medium on the fertilization and development of equine oocytes after in-vitro fertilization or intracytoplasmic sperm injection. Hum. Reprod. 12, 2766-72.

Dell'Aquila, M. E., Fusco, S., Lacalandra, G. M. \& Maritato, F. (1996). In vitro maturation and fertilization of equine oocytes recovered during the breeding season. Theriogenology 45, 547-60.

Dell'Aquila, M. E., Masterson, M., Maritato, F. \& Hinrichs, K. (2001). Influence of oocyte collection technique on initial chromatin configuration, meiotic competence, and male pronucleus formation after intracytoplasmic sperm injection (ICSI) of equine oocytes. Mol. Reprod. Dev. 60, 7988.

Galli, C., Crotti, G., Turini, P., Duchi, R., Mari, G., Zavaglia, G., Duchamp, G., Daels, P. \& Lazzari, G. (2002). Frozenthawed embryos produced by ovum pick up of immature oocytes and ICSI are capable to establish pregnancies in the horse. Theriogenology 58, 705-8.

Goudet, G. (2011). Fertilisation in the horse and paracrine signalling in the oviduct. Reprod. Fertil. Dev. 23, 941-51.

Goudet, G., Belin, F., Mlodawska, W. \& Bezard, J. (2000). Influence of epidermal growth factor on in vitro maturation of equine oocytes. J. Reprod. Fertil. Suppl. 56, 483-92.

Goudet, G., Bézard, J., Duchamp, G., Gérard, N. \& Palmer, E. (1997). Equine oocyte competence for nuclear and cytoplasmic in vitro maturation: effect of follicle size and hormonal environment. Biol. Reprod. 57, 232-45.

Hawley, L. R., Enders, A. C. \& Hinrichs, K. (1995). Comparison of equine and bovine oocyte-cumulus morphology within the ovarian follicle. Biol. Reprod. Monograph Series 1, 243-52.

Hinrichs, K. (2012). Assisted reproduction techniques in the horse. Reprod. Fertil. Dev. 25, 80-93.

Hinrichs, K., Choi, Y. H., Love, L. B., Varner, D. D., Love, C. C. \& Walckenaer, B.E. (2005). Chromatin configuration within the germinal vesicle of horse oocytes: changes post mortem and relationship to meiotic and developmental competence. Biol. Reprod. 72, 1142-50.

Hinrichs, K., Love, C. C., Brinsko, S. P., Choi, Y. H. \& Varner, D.D. (2002). In vitro fertilization of in vitro-matured equine oocytes: effect of maturation medium, duration of maturation, and sperm calcium ionophore treatment, and comparison with rates of fertilization in vivo after oviductal transfer. Biol. Reprod. 67, 256-62.

Kawashima, I., Okazaki, T., Noma, N., Nishibori, M., Yamashita, Y. \& Shimada, M. (2008). Sequential exposure of porcine cumulus cells to $\mathrm{FSH}$ and/or LH is critical for appropriate expression of steroidogenic and ovulationrelated genes that impact oocyte maturation in vivo and in vitro. Reproduction 136, 9-21.
Lange Consiglio, A., Dell'Aquila, M. E., Fiandanese, N., Ambruosi, B., Cho, Y. S., Bosi, G., Arrighi, S., Lacalandra, G. M. \& Cremonesi, F. (2009). Effects of leptin on in vitro maturation, fertilization and embryonic cleavage after ICSI and early developmental expression of leptin $(\mathrm{Ob})$ and leptin receptor $(\mathrm{ObR})$ proteins in the horse. Reprod. Biol. Endocrinol. 7, 113.

Lazzari, G., Crotti, G., Turini, P., Duchi, R., Mari, G., Zavaglia, G., Barbacini, S. \& Galli, C. (2002). Equine embryos at the compacted morula and blastocyst stage can be obtained by intracytoplasmic sperm injection (ICSI) of in vitro matured oocytes with frozen-thawed spermatozoa from semen of different fertilities. Theriogenology 58, 709-12.

Leemans, B., Gadella, B. M., Stout, T. A., Heras, S., Smits, K., Ferrer-Buitrago, M., Claes, E., Heindryckx, B., De Vos, W. H., Nelis, H., Hoogewijs, M. \& Van Soom, A. (2015). Procaine induces cytokinesis in horse oocytes via a $\mathrm{pH}$ dependent mechanism. Biol. Reprod. 93, 23.

Lopera-Vasquez, R., Hamdi, M., Maillo, V., Lloreda, V., Coy, P., Gutierrez-Adan, A., Bermejo-Alvarez, P. \& Rizos, D. (2015). Effect of bovine oviductal fluid on development and quality of bovine embryos produced in vitro. Reprod. Fertil. Dev. doi: 10.1071/RD15238. [Epub ahead of print]

Martino, N. A., Marzano, G., Nicassio, M., Minervini, F., Cardinali, A., Lacalandra, G. M., Hinrichs, K. \& Dell'aquila, M.E. (2016). Effects of verbascoside treatment during oocyte in vitro maturation on blastocyst development and bioenergetic/oxidative status after ICSI in the horse. J. Equine Vet. Sci. 41, 66.

McPartlin, L. A., Suarez, S. S., Czaya, C. A., Hinrichs, K. \& Bedford-Guaus, S.J. (2009). Hyperactivation of stallion sperm is required for successful in vitro fertilization of equine oocytes. Biol. Reprod. 81, 199-206.

Meyers-Brown, G., Bidstrup, L. A., Famula, T. R., Colgin, M. \& Roser, J.F. (2011). Treatment with recombinant equine follicle stimulating hormone (reFSH) followed by recombinant equine luteinizing hormone (reLH) increases embryo recovery in superovulated mares. Anim. Reprod. Sci. 128, 52-9.

Mugnier, S., Kervella, M., Douet, C., Canepa, S., Pascal, G., Deleuze, S., Duchamp, G., Monget, P. \& Goudet, G. (2009). The secretions of oviduct epithelial cells increase the equine in vitro fertilization rate: are osteopontin, atrial natriuretic peptide A and oviductin involved? Reprod. Biol. Endocrinol. 7, 129.

Palmer, E., Bezard, J., Magistrini, M. \& Duchamp, G. (1991). In vitro fertilization in the horse. A retrospective study. J. Reprod. Fertil. Suppl. 44, 375-84.

Smits, K., Govaere, J., Hoogewijs, M., Piepers, S. \& Van Soom, A. (2012a). A pilot comparison of laser-assisted vs piezo drill ICSI for the in vitro production of horse embryos. Reprod. Domest. Anim. 47, e1-3.

Smits, K., Hoogewijs, M., Woelders, H., Daels, P. \& Van Soom, A. (2012b). Breeding or assisted reproduction? Relevance of the horse model applied to the conservation of endangered equids. Reprod. Domest. Anim. 47(Suppl. 4), 239-48.

Tremoleda, J. L., Stout, T. A., Lagutina, I., Lazzari, G., Bevers, M. M., Colenbrander, B. \& Galli, C.(2003). Effects of in vitro 
1110 production on horse embryo morphology, cytoskeletal 1111 characteristics, and blastocyst capsule formation. Biol. 1112 Reprod. 69, 1895-906.

1113 Zhang, J. J., Boyle, M. S., Allen, W. R. \& Galli, C. 1114 (1989). Recent studies on in vivo fertilization of in vitro matured horse oocytes. Equine Vet. J. Suppl. 8, 1115 $101-4$.

Zhang, J. J., Muzs, L. Z. \& Boyle, M.S. (1990). In vitro 1117 fertilization of horse follicular oocytes matured in vitro. 1118 Mol. Reprod. Dev. 26, 361-5. 